\title{
Effect of head width, head height and clamp force on the noise reduction provided by two different styles of earmuffs
}

Jonathan R. Lewin

West Virginia University

Follow this and additional works at: https://researchrepository.wvu.edu/etd

\section{Recommended Citation}

Lewin, Jonathan R., "Effect of head width, head height and clamp force on the noise reduction provided by two different styles of earmuffs" (2013). Graduate Theses, Dissertations, and Problem Reports. 529.

https://researchrepository.wvu.edu/etd/529

This Thesis is protected by copyright and/or related rights. It has been brought to you by the The Research Repository @ WVU with permission from the rights-holder(s). You are free to use this Thesis in any way that is permitted by the copyright and related rights legislation that applies to your use. For other uses you must obtain permission from the rights-holder(s) directly, unless additional rights are indicated by a Creative Commons license in the record and/ or on the work itself. This Thesis has been accepted for inclusion in WVU Graduate Theses, Dissertations, and Problem Reports collection by an authorized administrator of The Research Repository @ WVU. For more information, please contact researchrepository@mail.wvu.edu. 
Effect of head width, head height and clamp force on the noise reduction provided by two different styles of earmuffs

\author{
Jonathan R. Lewin
}

\author{
Thesis submitted \\ to the College of Engineering and Mineral Resources \\ at West Virginia University \\ in partial fulfillment of the requirements for the degree of \\ Master of Science in \\ Industrial Hygiene
}

Steven Guffey, Ph.D., Chair

Ashish Nimabarte, Ph.D.

M. Abbas Virji, Sc.D.

Department of Industrial and Management Systems Engineering

Morgantown, West Virginia

2013

Keywords: clamp force, earmuff, attenuation

Copyright 2013 Jonathan Lewin 


\begin{abstract}
Effect of head width, head height and clamp force on the noise reduction provided by two different styles of earmuffs

Jonathan R. Lewin
\end{abstract}

Earmuffs provide necessary protection from the hazardous effects of noise for workers and the general population. The wearability and effectiveness of these devices is crucial for protection of hearing in noisy conditions. One component critical to the function of the earmuff is the clamp force that keeps the earmuff securely against the head and around the pinna. This clamp force must be high enough to provide a good seal, but not so high that it makes the muff uncomfortable. This study investigated the relationship between noise reduction (NR) and the force on the ear. This force was incrementally varied by attaching counter weights, ranging from 200-1200 grams, to the muffs. The NR values for four (4) muffs used by six (6) human subjects were determined in a reverberation chamber using the MIRE test method. Each muff-subject combination was tested twice. When all muffs were considered as a group, at least one NR test value was below $10 \mathrm{dBA}$ for test forces in the range of 0.9-2.3 lbs. However, if the Bilsom was not considered, there were no NR $<15 \mathrm{dBA}$ for 2-2.3 lbs. For the other muffs, the minimum force needed to assure NR $>15 \mathrm{dBA}$ was $1.95 \mathrm{lbs}$. It is doubtful that increasing the total force would improve performance further. As expected NR values fell with decreasing force on the ear $(\mathrm{p}<0.01)$. Subject, MuffId and the interaction of MuffId and Subject all showed significance $(\mathrm{p}$ $<0.001)$. 


\section{TABLE OF CONTENTS}

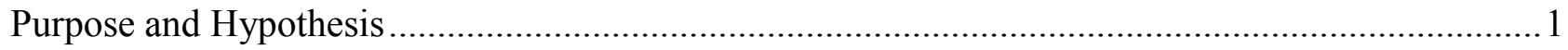

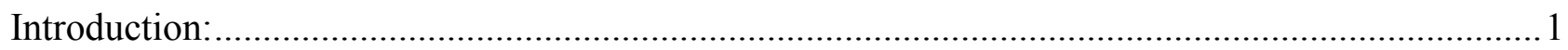

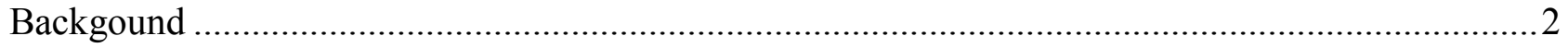

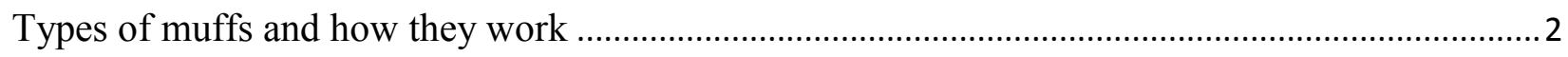

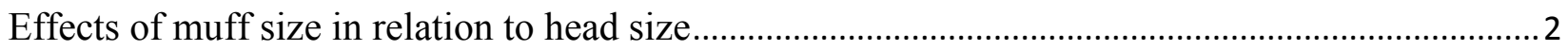

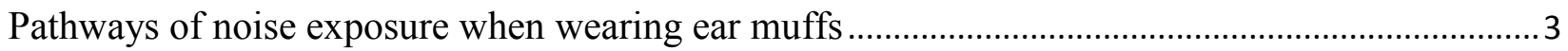

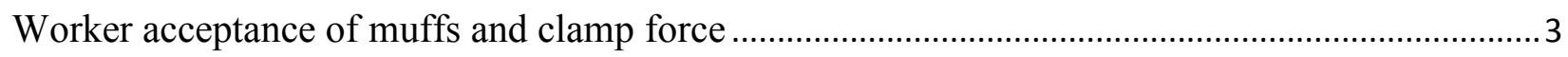

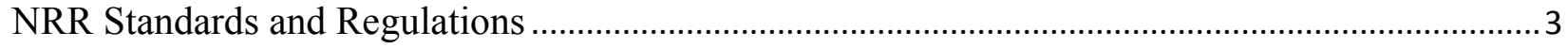

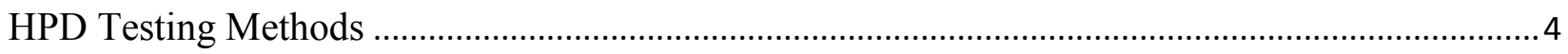

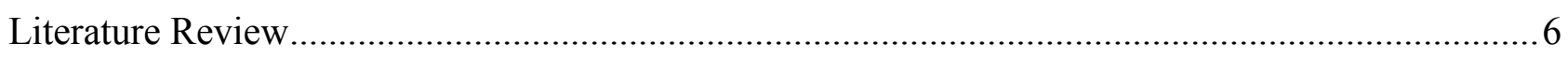

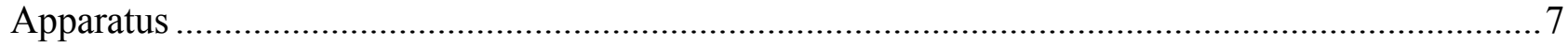

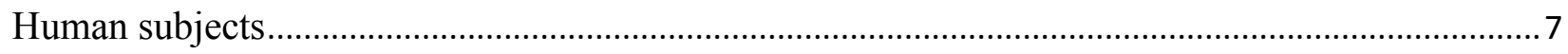

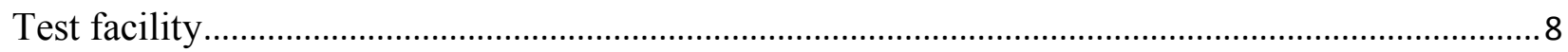

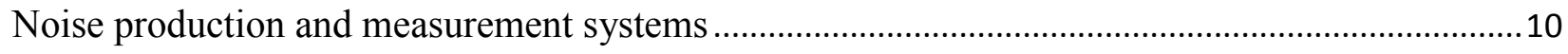

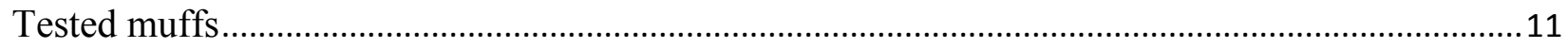

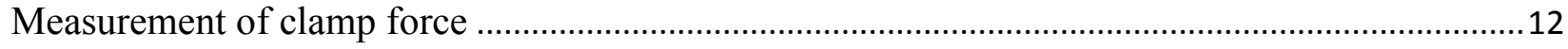

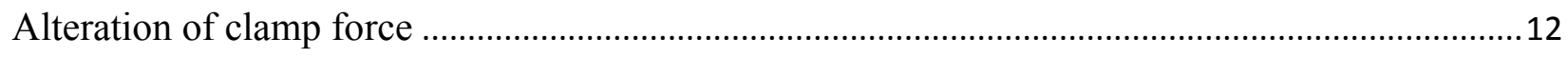

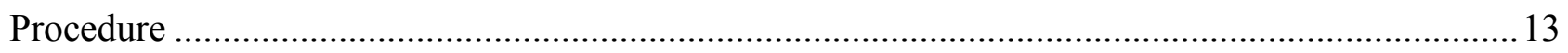

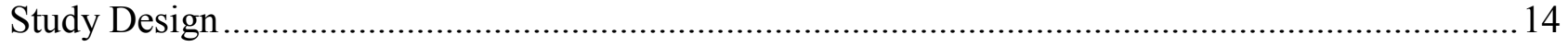

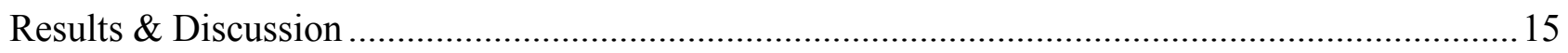

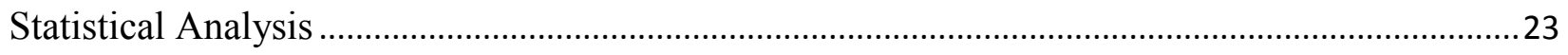

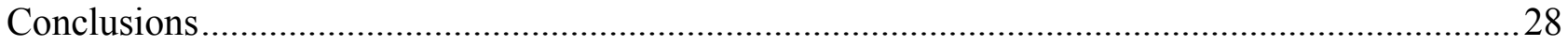

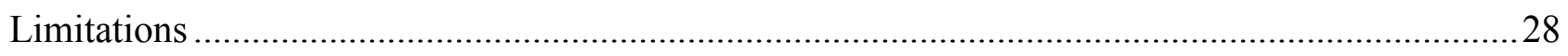

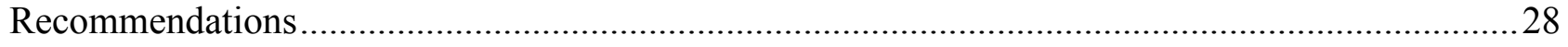

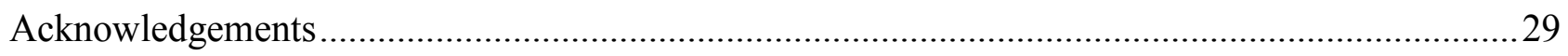

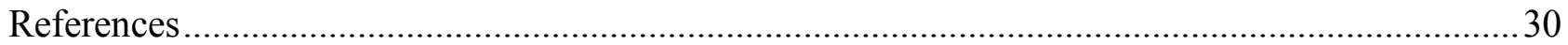




\section{Tables and Figures}

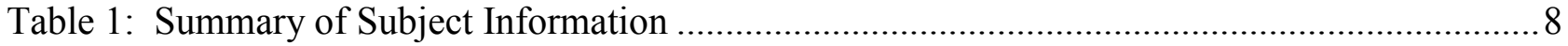

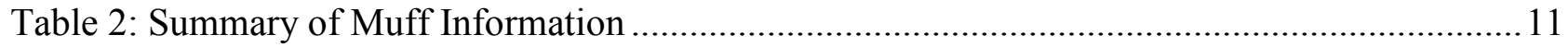

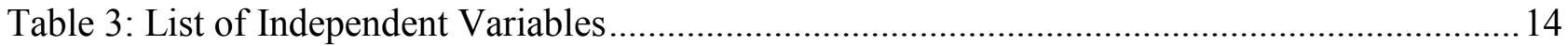

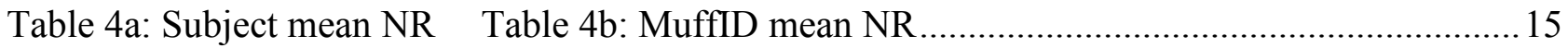

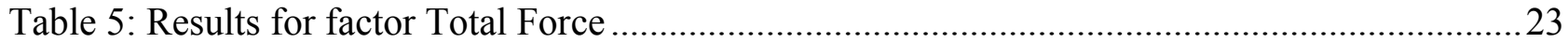

Table 6: Results when MuffID, Total Force, Subject are added to the Model for $0-2.3 \mathrm{lbs}$...........24

Table 7: Results when MuffID, Total Force, Subject are added to the Model for $1.5-2.3 \mathrm{lbs}$........24

Table 8: Scheffe Post Hoc Test - Differences between MuffID .........................................................2.

Table 9: Scheffe Post Hoc Test - Differences between Subjects .....................................................25

Table 10: Coefficients for Model for $\mathrm{NR}_{\mathrm{dBA}}$ for $0-2.3 \mathrm{lbs}$ Total Force ............................................26

Table 11: Coefficients for Model for $\mathrm{NR}_{\mathrm{dBA}}$ for 1.5-2.3 lbs Total Force .......................................2

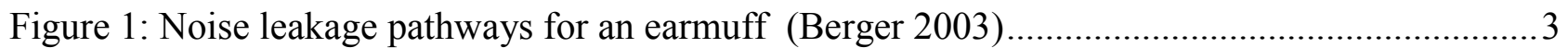

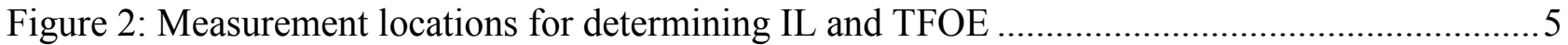

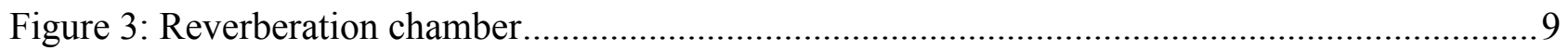

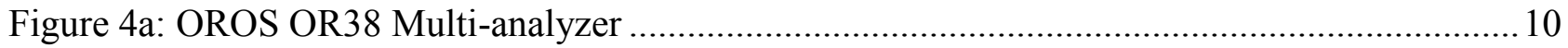

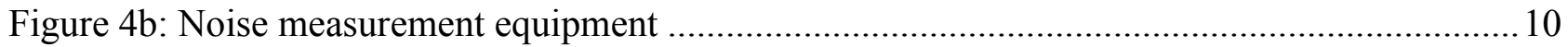

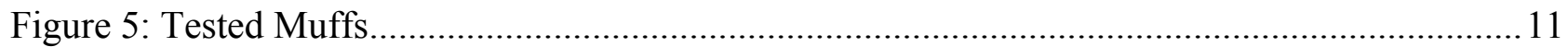

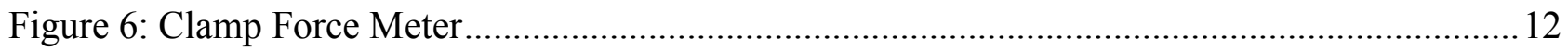

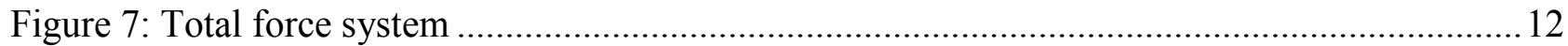

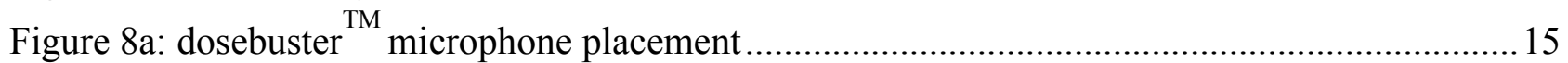

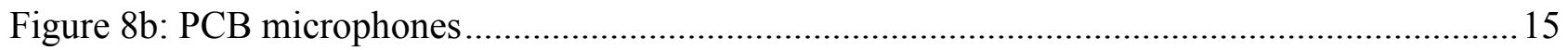

Figure 9: NR observed for each subject and each earmuff........................................................... 16

Figure 10: Comparison of each subject's percentage change from $\mathrm{NR}_{\text {baseline }}$ at $200 \mathrm{gm}(0.4 \mathrm{lbs})$....17

Figure 11: Comparison of each subject's percentage change from $\mathrm{NR}_{\text {baseline }}$ at $400 \mathrm{gm}(0.9 \mathrm{lb})$......18

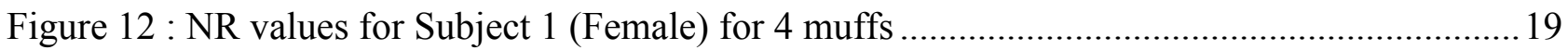

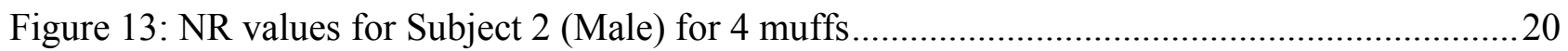

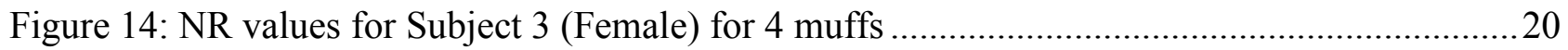

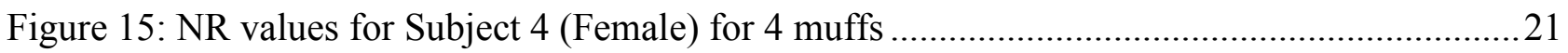

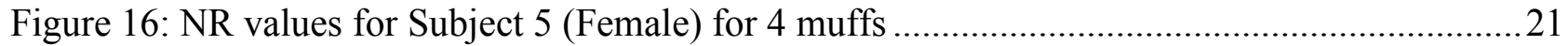

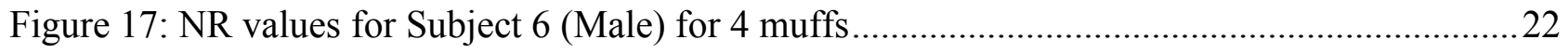

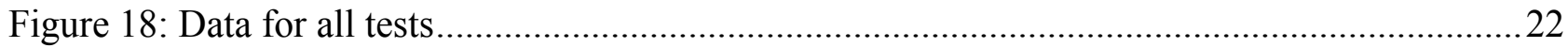




\section{PURPOSE AND HYPOTHESIS}

The purpose of this study is to examine the effect of face width, face height and variations in clamp force (using weights and pulleys) has on the attenuation of 4 different earmuffs. Six human subjects are tested using the microphone-in-real ear (MIRE) method with 2 different models of over-the-head earmuffs and 2 different models of cap-mounted earmuffs.

This study is needed because the published research involving clamp force did not employ the unique method of varying the clamping force of the earmuff used in this study.

The following hypotheses will be tested:

NR will be greater with higher Total Force:

$\mathrm{H}_{0}: \mathrm{NR}=$ constant for all tests

$\mathrm{H}_{1}$ : NR decreases with decreasing Total Force

where: $\mathrm{NR}=$ Noise reduction

Total Force $=$ Clamp force - weight

\section{INTRODUCTION:}

Noise continues to be a significant hazard in most work environments. The effects of chronic noise exposure and the resulting noise-induced hearing loss (NIHL) can be detrimental on a worker's quality of life (Berger 2003). The use of engineering controls is the best approach to combating noise hazards but their implementation is often stalled due to feasibility and economic considerations. Personal protective equipment (PPE) is often used to provide hearing protection for a worker exposed to noise. The most common type of PPE provided to a worker is a passive hearing protection device (HPD).

Circum-aural (earmuffs) and intra-aural (earplugs) hearing protectors are the two leading types of passive HPD used in general industry, construction and mining. These devices protect a worker by interrupting the noise transmission path from the source to the receiver. For an earmuff to effectively interrupt the noise, the correct positioning and fit must be sustained for the length of the exposure. Differing facial topography and comfort can impact the fit and wearability of an earmuff. If a worker perceives his or her earmuff to be uncomfortable or constraining, they will be less likely to wear it continuously and in the correct position (Casali et al, 1990).

The clamp force (i.e. the force exerted by the spring system in the earmuff) is often regarded as the largest contributor to discomfort (Williams 2007, Casali et al, 1990). Based on the British 
Standard, which sets the maximum force of an earmuff at $16 \mathrm{~N}(3.6 \mathrm{lbs}$.), it is assumed that a substantial clamp force (e.g., $\geq 2 \mathrm{lbs}$ ) is needed for adequate attenuation (Berger et al, 1989). It is unclear whether a nominally decreased clamp force could provide sufficient attenuation. However, forces above $2.0 \mathrm{lbs}$ have been shown to reduce comfort. Hsu, Huang, Yo, Chen and Lien (2004) stated that the force under $10.5 \mathrm{~N}$ (2.4 lbs) would be described by $80 \%$ of the wearers as "no particular feeling" or "a little tight". This study aims to investigate the relationship between clamp force and the attenuation provided by 4 commonly used earmuffs.

\section{BACKGOUND}

The different types of earmuffs and how they reduce the transmission of noise to the ear are discussed in this section. Additionally, worker acceptance to earmuffs, relevant standards and regulations for muff effectiveness are discussed, as are the test methods used to determine earmuffs' effectiveness.

\section{Types of muffs and how they work}

Two types of earmuffs exist: over-the-head and cap-mounted. The over-the-head style uses an adjustable spring band that fits over the top of the head. Variations of the over-the-head style earmuff exist that allow a wearer the option of placing the band under the chin, behind the head or over the head (Berger 2003). Altering the placement of the band does in some cases change the amount of protection that the muff affords a wearer, but may be necessary to allow the use of specialized protective equipment, such as some powered air purifying respirators.

The other type of earmuff is the cap-mounted or capmuff, which consists of a muff attached to a hard hat using spring arms that are either permanently attached to the helmet or snap into slots in the helmet. This type of protective equipment is used predominantly in construction and mining where the risks from falling objects are coupled with the risk of hearing loss from high exposures to noise.

Most earmuffs are comprised of a hard plastic outer shell called the "cup", a noise attenuating acoustical material within the cup (e.g., open cell foam) and circum-aural cushions filled with a liquid, gel or foam that seal against the head. The force exerted by the band compresses the cushion against the skin around the outer ear, thus providing the seal (Berger 2003).

\section{Effects of muff size in relation to head size}

One difficulty with earmuffs is the perhaps insufficient variety of shapes and sizes in common use. For example, most standard earmuffs or cap-mounted earmuffs are issued to workers by employers in a single size. Since stretching the band to fit the head creates the clamp force, those with smaller heads will experience a lower force that may be insufficient to provide the sealing 
necessary to obtain adequate protection. On the other hand, those with larger heads may find their much higher clamp force to be painful or uncomfortable, which in turn may lead to avoidance of wearing the earmuff when it is needed.

\section{Pathways of noise exposure when wearing ear muffs}

Noise can reach the inner ears of the person wearing an earmuff by one or more of the pathways outlined and illustrated in Figure 1 (Berger 2003)

The maximum possible protection an earmuff can provide a user from noise through these pathways is greatly dependent on the frequency of the noise. At low frequencies, such as $125 \mathrm{~Hz}$, an earmuff's ability to attenuate noise is somewhat limited due to vibrations of the HPD and bone conduction (Berger 2003).

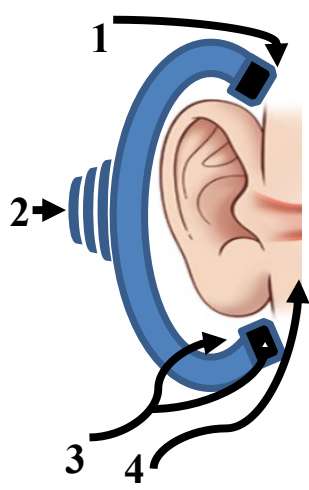

(1) leak by the protector, (2) protector vibrations transmission through protector materials, (4) bone conduction

Figure 1: Noise leakage pathways for an earmuff (Berger 2003)

\section{Worker acceptance of muffs and clamp force}

A worker's acceptance of the earmuff is strongly dependent on comfort, which can vary from one person to another with the same muff and can vary greatly with different individuals using the same muff. Casili et al, (1990) provided a thorough synopsis of studies that had investigated the influence that clamp force, cushion pressure and earmuff total mass have on comfort. In most studies clamp force did not show a direct relationship with comfort. Earmuffs with a higher clamp force were not always observed to be the most uncomfortable.

It is reasonable to assume that noise attenuation (NR) provided by the earmuff increases with clamp force. Since the force increases as the earmuff springs are extended, a person with a larger head would experience a greater clamp force and therefore achieve greater protection and sometimes greater discomfort than a person with a smaller head. Earmuffs available on the market have a wide range of clamp forces. The ideal clamp force would assist in keeping the cushion secure on the head; provide enough deformation of the cushions to adequately seal the cushion to the side of the head while being low enough to minimize discomfort.

\section{NRR Standards and Regulations}

Manufacturers' of muff are required by EPA (40 CFR 211, Product Noise Labeling, Subpart B Hearing Protection Devices top) to provide specific labeling and rating evaluations of HPDs. Under this rule, manufacturers of HPDs are required to determine the Noise Reduction Rating (NRR) using the referenced method ANSI S3.19 -1974, "Method for the measurement of real-ear 
protection for hearing protectors and physical attenuation of earmuffs." This method tests a panel of human subjects under laboratory conditions.

The purpose of the NRR is to give industry managers, professionals and employees as well as the general public an easily identifiable means to determine the attenuation capabilities an individual wearing a particular HPD could attain. However, the consensus within the noise research community is that this standard needs updated. Mostly because it is believed that the estimated protection is higher than is achieved at work sites (Berger 2003, Durkt 1993).

Apparently agreeing that NRR values inflate performance, the Occupational Health and Safety Association (OSHA) "de-rates" the NRR. If noise measurements are made with the dBA scale, the following equation applies;

$$
\mathrm{SPL}_{(\mathrm{dBA})} \text { at ear }=\mathrm{SPL}_{(\mathrm{TWA})}-(\mathrm{NRR}-7) / 2
$$

If the noise level measurements are made with the $\mathrm{dBC}$ scale, the following formula applies:

Noise level $-\mathrm{NRR} / 2=\mathrm{SPL}(\mathrm{dBC})$ at ear

The National Institute of Occupational Health and Safety (NIOSH) has a different approach to the presumed NRR overestimation. They reduced the published NRR by $25 \%$ for earmuffs, $50 \%$ for foam earplugs, and $70 \%$ for other types of earplugs. It's important to note that earmuffs are de-rated the least and there is no distinction made between over the head and cap-mounted earmuffs.

One interesting proposal by the EPA is the requirement of the number of subjects for testing purposes. 10 subjects are to be tested with earmuffs or helmets and 20 subjects be tested on earplugs and semi-aural devices. The reduction in needed subjects is likely due to the fact that subject error is far less with earmuffs, so the ability to properly fit the earmuff far greater. From a data collection perspective the variability of a subject to get a similar fit with earplugs is much higher than with earmuffs. ANSI S12.6-2008 specifies that 20 subjects shall be tested on capmounted earmuffs, which the EPA proposal does not explicitly state.

\section{HPD Testing Methods}

There are two primary methods of evaluating the attenuation of an HPD; "Real ear attenuation" (REAT) or "microphone in real ear" (MIRE). REAT is a subjective, audiometric test that measures the difference between what noise stimulus a subject can hear without an HPD (openear) versus what a subject can hear with the HPD in place (occluded ear). The difference between the open ear and the occluded ear is the insertion loss (IL) or;

$$
\mathrm{IL}=\mathrm{SPL}_{(\text {open ear) }}-\mathrm{SPL}_{\text {(occluded ear) }}
$$

Where: IL $=$ insertion loss in decibels 
REAT is the primary method used by manufactures in the United States to test the attenuation of an HPD. REAT is considered the "gold standard" of all the laboratory HPD test methods. REAT is considered the most accurate and solid means of determining the effectiveness of passive HPDs (Berger 2005, Berger 2003, Berger 1986). Berger argues that the IL values generated by using REAT provide the best indicator of the performance of HPDs.

ANSI developed another method to evaluate the fit and attenuation value of an HPD, the MIRE. ANSI describes this method in S12.42-1995, "Microphone-in-Real-Ear and Acoustical Test Fixture Methods for the Measurement of Insertion Loss of Circumaural Hearing Protection Devices."

MIRE physically measures the noise stimulus inside the HPD and outside the HPD simultaneously or before and after a HPD is applied using two microphones. The equation for this measurement is as:

$$
\mathrm{NR}=\mathrm{SPL} \text { (outside) }-\mathrm{SPL}_{\text {(inside) }}
$$

Where: $\mathrm{NR}=$ noise reduction due to an earmuff or earplug

Due to the physiology of the ear, which creates resonance and amplifies sound, the SPL outside the entrance of the canal is not accurately measured using a microphone (Berger 2005). Figure 2 illustrates the relationship between IL and NR. The difference between the IL and NR is the "transfer function of the open ear" (TFOE):
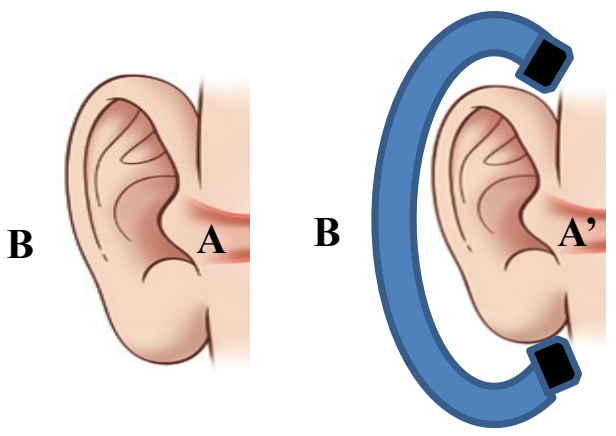

Figure 2: Measurement locations for determining IL and TFOE

$\mathrm{TFOE}=\mathrm{NR}-\mathrm{IL}$

Both the MIRE and REAT methods have limitations and benefits in assessing the attenuation value of an HPD. In most cases it depends on the environment and purpose in which the testing is occurring. REAT requires the use of a quiet environment or sound proof booth to eliminate the potential for background contamination or bias of the data (Berger 2005). MIRE is not based on the subject's awareness of noise and is therefore better suited for field studies.

Durkt (1993) used the MIRE method to evaluate the effectiveness of earmuffs in real time mining environments. Through wireless signal transmission, a microphone was placed under the earmuff, while the other was on earmuff cup outside. This is seems to be justifiable placement of the outside microphone. The study, however, indicated a high level of variability between subjects. 
For this study, the best test method was MIRE. The incremental reduction in the earmuff's clamping force by the weight and pulley system would have interfered with the subject's perceived noise stimulus. MIRE allowed for the data to be collected objectively as the earmuff's effectiveness decreased or increased randomly for each subject.

\section{LITERATURE REVIEW}

This review of the literature concentrates on published studies of the effects of clamp force on earmuff attenuation. As is discussed, several relevant studies were found. However, despite diligent efforts no studies were found that described experiments where clamp force was varied using a weight and pulley system as was done in this study.

Johnson et al, (1983) determined the NR for 3 human subjects and one manikin while progressively reducing the clamp force of five (5) different muffs until the force was less than 1 pound. In 4 of the 5 muffs tested, NR for the manikin fell by $3 \mathrm{~dB}$ when the clamp force was reduced by $50 \%$ from its original value for each subject. The fifth muff had a far greater sensitivity to the $50 \%$ reduction in clamp force and resulted in a 50\% decrease in NR. This abstract did not provide any detail as to methodology and the author was unable to obtain the full manuscript.

Williams (2007) examined 39 earmuffs used in industry and commercially. This study suggested that that clamp force may not play a large role in the overall attenuation of the earmuff; rather the clamp force may only be necessary to keep the earmuff in place so that the cushion and the noise absorbing material inside the muff can attenuate the noise. Data was collected on 16 test subjects using 1/3 octave band pink noise. Clamp force was measured by affixing the earmuff to a fixed, flat, horizontal surface set at a separation distance of $14.5 \mathrm{~cm}$. Using a white sheet and pre-inked cushion, the surface area impression remaining after the depression of the earmuff was then measured. The study produced data (mean clamp force $10.9 \mathrm{~N}(2.5 \mathrm{lbs})$ with a standard deviation of 2.2) to conclude that there is no significant statistical correlation between clamp force and attenuation. The study was specifically examining the current mean force of the 39 various earmuffs and whether it is sustainable for a worker to wear earmuffs for an entire shift.

A study performed by Zannin et al, (2005) examined three of the four leak pathways identified by Berger: protector vibrations, transmission through protector materials and a leak through protector and wearer. Correlation between the clamp force and attenuation of low frequencies in that at maximal deformation of the cushion a $20 \mathrm{~dB}$ reduction was achieved at a frequency of 200 Hz. Noise data was measured using the MIRE method. Clamp force measurements were taken using a clamp force meter. The study evidenced that clamp force may only be useful in assisting with attenuation of low frequencies. Higher frequencies would be attenuated by components of the earmuff such as the open cell foam that lines the inside of the cup. 
Kortarbinska (2005) investigated the effects of use, outdoor conditions and general storage on 4 types of over the head earmuffs over a three year period. Head band force or cushion pressure data was collected in accordance with EN 352-1. Noise attenuation data was collected in accordance with EN 24869-1. The study had a large variance in how the experimental conditions affected clamp force and attenuation for the 4 over the head models tested. Model 1 was impacted the most showing a modest reduction in clamp force of $8.3 \%$ for general use with a decrease in attenuation of $9.1 \mathrm{~dB}$ for high frequencies. A $23.6 \%$ reduction was observed for samples exposed to the outdoors with an overall reduction in attenuation of $10.1 \mathrm{~dB}$. Model 2 , however, exposed to the exact same conditions, showed an average reduction in clamp force of only $0.87 \mathrm{~N}$ or $0.19 \mathrm{lbs}$-force with the attenuation remaining stable through the three years. The third muff showed a similar resilience with an average reduction attenuation of $2.3 \mathrm{~dB}$ and the clamp force with little to no change.

Hsu et al, (2004) examined 28 commercial over-the-head earmuffs in regards to temperature and clamp force as it relates to comfort and airtightness. The clamp force of the earmuffs was measured using a clamp force meter in accordance with EN352-1. The earmuffs were worn and rated by subjects as to what they perceived as comfortable. The results did not show any correlation between clamp force, temperature and airtightness. An additional part of the study modified two earmuffs so the clamp force could be adjusted to various forces. These forces were tested for airtightness and correlation was found. Airtightness in this case would be assumed to be leakage though the cushion, which would reduce the given attenuation of the earmuff.

\section{APPARATUS}

This study required the use of human subjects who were tested in a specially designed chamber. Each subject donned 4 muffs. Data was collected using specialized noise measurement and production equipment.

\section{Human subjects}

The subjects for this study consisted of 3 male and 3 female college students ranging from the ages of 24-39 years of age; see Table 1 for summary of subjects.

Each subject's head height was measured by placing the subject against a flat door with graphing paper affixed to it. A line is placed at the very top of the subject's head using a Swanson Speedlite square (Frankfort, IL) with an incorporated level. Another line is drawn by placing the square at the top of the canal. The distance between the two lines is measured using an Absolute Digimatic (Kawasaki, Japan) digital caliper. The head width was measured using spreading GMP Swiss made calipers. The spreading caliper tips were placed above the tragus. The subject's head height and width measurement data was then used to make adjustments to the 
clamp force meter. Each subject's clamp force for each muff was then obtained. Adiposity was observed for each subject.

Table 1: Summary of Subject Information

\begin{tabular}{llcccl}
\hline Subject & Sex & Height $(\mathrm{cm})$ & Width $(\mathrm{cm})$ & Age & Adiposity \\
\hline 1 & Female & 10.9 & 13.9 & 27 & Low \\
2 & Male & 13.2 & 14.5 & 24 & High \\
3 & Female & 12.6 & 13.4 & 25 & Low \\
4 & Male & 12.3 & 15.4 & 29 & Moderate \\
5 & Female & 11.6 & 13.7 & 24 & Moderate \\
6 & Male & 12.8 & 15.7 & 39 & Low \\
\hline
\end{tabular}

\section{Test facility}

Noise experimentation was conducted in the WVU IH laboratory MIRE-compliant sound chamber, specifically designed to maximize reverberation and establish a diffuse sound field. Preliminary assessments of the chamber were performed. It was determined that absorption of some higher frequencies did occur. This was corrected by adding the decrements from uniform frequency levels to measured noise levels at each one-third octave band. 


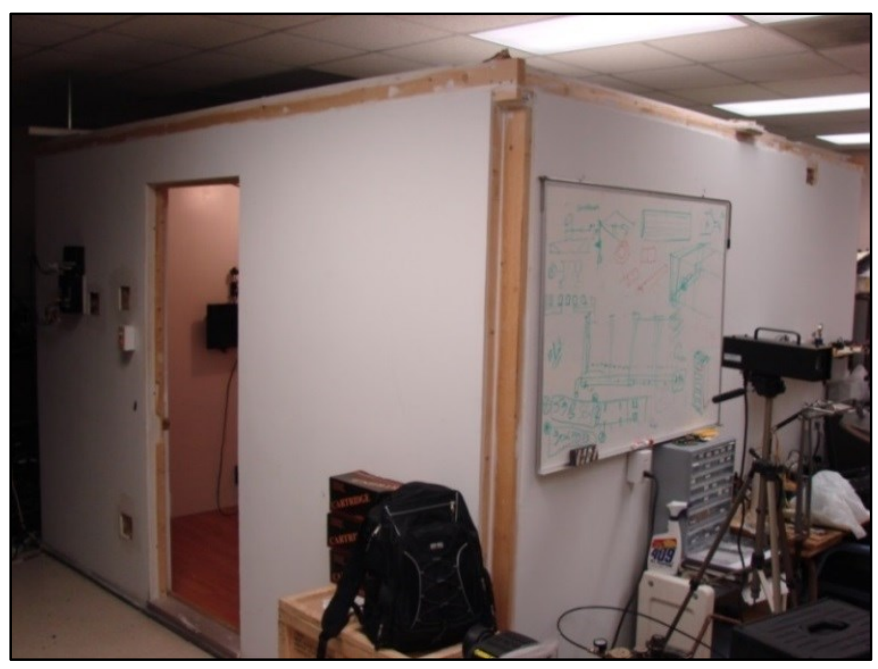

Figure 3: Reverberation chamber

The reverberation chamber (see Figure 3) measures 9'1" x 11'3" x 7'5" with a total volume of 758 cubic feet. The walls and ceiling are 2" x 4" frame construction finished with dry wall over $3 / 8$ " plywood while the floor is hard wood. The inner surfaces were painted with 3 coats of paint to improve reverberation. 


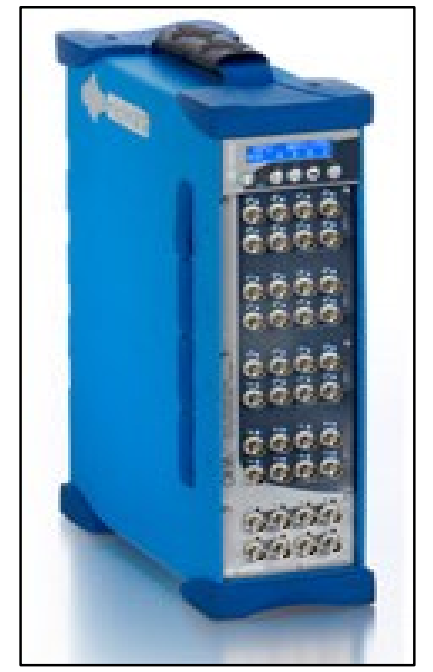

Figure 4a: OROS OR38 Multi-analyzer

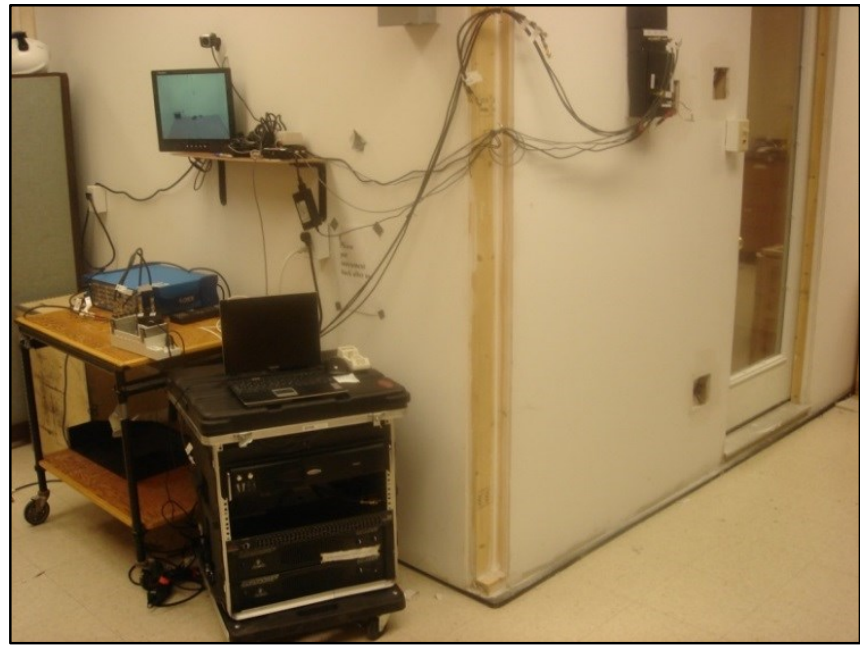

Figure 4b: Noise measurement equipment

\section{Noise production and measurement systems}

An OROS OR38 (Dullas,Va) multi-analyzer recorder (see Figure 4a) was used to generate the pink noise stimulus and record the resulting sound pressure levels. The OR38 has the capability to simultaneously analyze different inputs in $1 / 3$ octave band frequencies.

Three inputs consisting of two dosebuster ${ }^{\mathrm{TM}}$ (Pennsylvania, PA) microphones and one PCB Piezotronic (Depew, NY) microphone were utilized for transmission of noise levels to the OROS multi-analyzer. The dosebuster ${ }^{\mathrm{TM}}$ microphones were used to obtain the NR data and the PCB microphone was used as reference to ensure the system and chamber were functioning properly.

A Toshiba laptop (see Figure 4b) was interfaced with the OROS analyzer through NVGate, the OROS noise and vibration software platform. NVGate provides the means to communicate and set-up the OR38, acquire the measurements in a transferable format and calibrate the system. The OROS system was calibrated before and after each session using a Quest Technologies OC-10 calibrator set at $114.0 \mathrm{~dB}$ and $1000 \mathrm{~Hz}$. The OR38 was additionally interfaced with the Behringer Model \# EP1500 amplifier to generate the pink noise stimulus. The amplifier powered the Infiniti Primus Model \#160 speakers and DDX model \#131 equalizer. 
Table 2: Summary of Muff Information

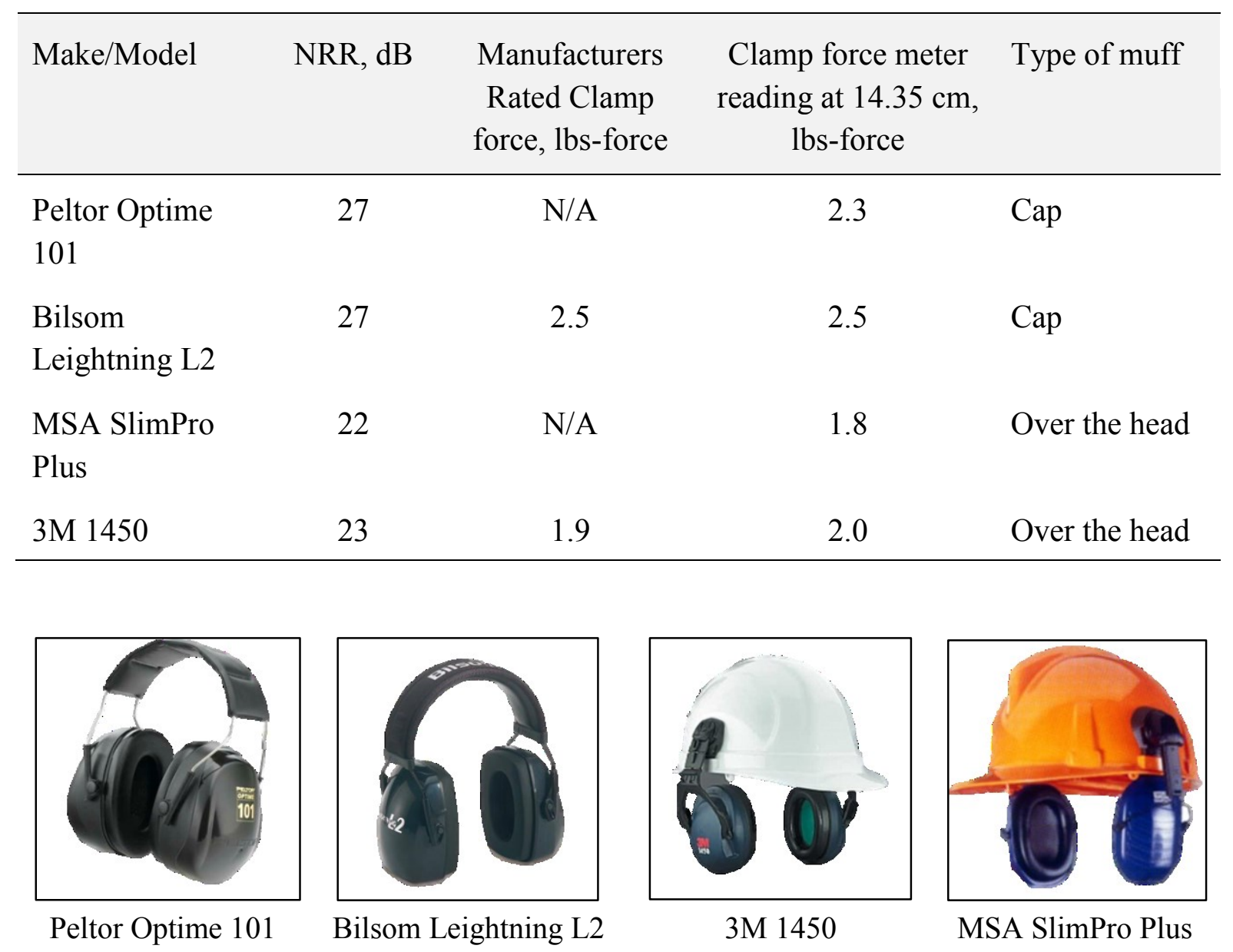

Figure 5: Tested Muffs

\section{Tested muffs}

Two cap-mounted earmuffs and two over the head earmuffs were used in the study, see Table 2 and Figure 5. These earmuffs represent typical styles used throughout general industry, mining and construction. 


\section{Measurement of clamp force}

As shown in Figure 6, clamp force measurements for the earmuffs used in this study were obtained using an ANSI compliant clamp force meter designed by Dr. Kevin Michael. The clamp force meter can be adjusted vertically or horizontally. The output for the meter is in lbs-force.

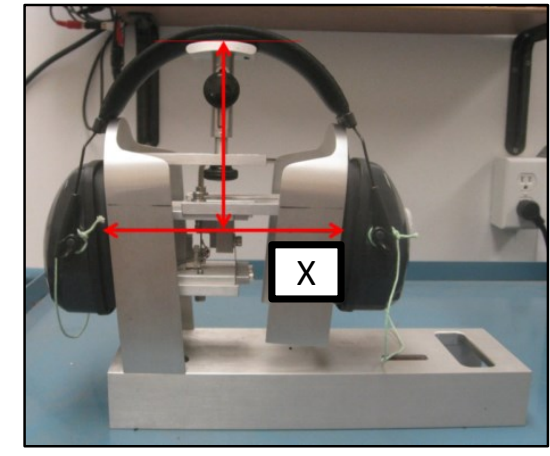

Figure 6: Clamp Force Meter

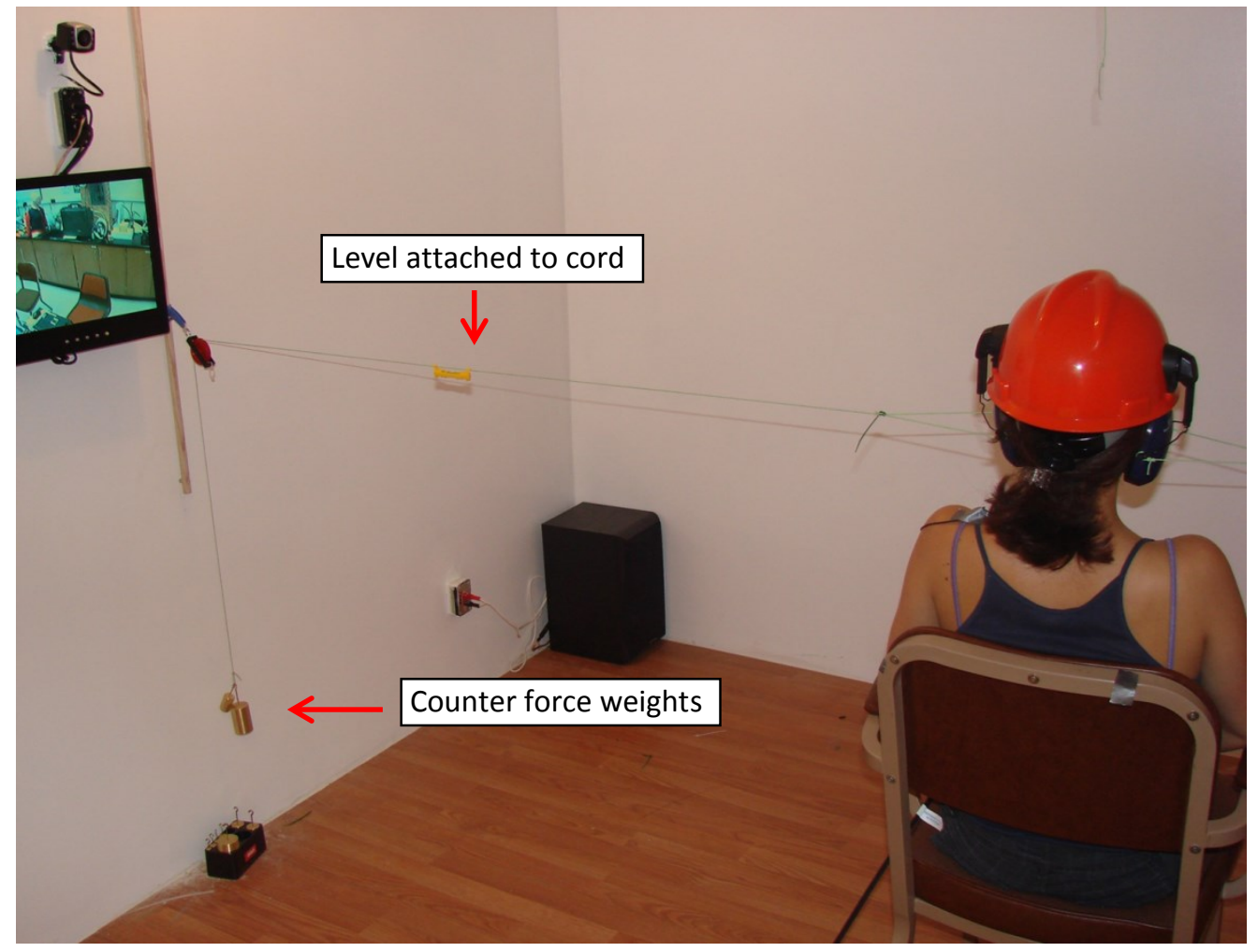

Figure 7: Total force system

\section{Alteration of clamp force}

OHAUS weights (Parsippany, NJ) were used with pulleys and cloth string to reduce the clamp force in increments of 200 grams; 200, 400, 6008001000 and 1200. [see Figure 7] 


\section{PROCEDURE}

Before each test session, two dosebuster ${ }^{\mathrm{TM}}$ microphones and one PCB microphone are calibrated using a Quest OC-10 calibrator at $114.0 \mathrm{~dB}$ and $1000 \mathrm{~Hz}$. The noise signal sound pressure level (SPL) is then tested and set to $100 \mathrm{~dB}$. The subject was placed inside the reverberation chamber on a plastic chair in the middle of the room. The subject faced the back wall to allow for the test ear to be viewed by a live feed video camera. The center of subject's head was aligned with the diffuse field indicator which was suspended from the ceiling.

The open ear or inside earmuff microphone was taped on the subject's ear insuring that the microphone tip was centered to the canal. The subject was given instructions to eliminate as much subject distortion as possible. This included such items as remaining still and quiet during noise generation and testing, to refrain from swallowing while noise is being generated and data was collected. The subject was also informed that after each set they would be required to pick numbers and communicate with the experimenter (see Appendix A) for randomization setup. The subject additionally was given a foam ear plug for the right, untested ear.

An open ear test was taken first using the pink noise generated from the OR38. The noise duration lasted 10 seconds; this was the duration of each test administered. Subjects wore one of 4 muffs, one at a time in random order until they had been tested with each muff. The subject was asked to give a number between one and eight for earmuff selection and a number between one and five for weight size selection.

The earmuffs were placed on the subject with assistance from the experimenter. The subject was asked to adjust the muff to a comfortable position where the band was resting on the top of the head and they felt they were obtaining a good seal with the cushion of the earmuff. Once the corresponding earmuff was selected and fitted to the subjects comfort, cloth strings were affixed to both earmuffs using plastic cable zip ties and run through a pulley on each side. The outside microphone was placed on the outside of the earmuff connected by a Velcro assembly. Scale weights of $200,400,600,800,1000$ or 1200 grams were attached simultaneously to the string at the opposite end of the strings on both sides. The addition of these weights to the muff provided a total force value. The total force is then calculated in the following equation;

Total Force $=$ Clamp Force - weight applied

Two bubble levels were attached to each string to ensure a mostly horizontal plane from the weight to the earmuff (see Figure 6). All weights were tested for a given muff before switching to the next muff.

Pink noise was produced by the speakers at a fixed noise level of $100 \mathrm{~dB}$. One-third octave noise levels were measured in the center of the chamber, directly outside of the earmuff and at the opening to the ear inside the earmuff concurrently. Each of the 6 subjects was tested twice at 
each weight with both tests at each weight done in a single randomized order. Both insertion loss (IL) and noise reduction (NR) were computed from these values for each test condition.

At the end of each earmuff testing session for each subject a leak test was performed to determine if the dosebuster ${ }^{\mathrm{TM}}$ microphone cord or the duct tape used to hold the microphone in place compromised the seal of the earmuff. This test consisted of comparing the measured NR values using an earmuff with the setup used in this study, i.e. duct tape and cord between the cushion and an earmuff with the cord placed through a drilled section of the earmuff. Additionally, each of the three microphones used were post calibrated using a Quest OC-10 calibrator at $114.0 \mathrm{~dB}$ and $1000 \mathrm{~Hz}$.

\section{STUDY DESIGN}

To determine the minimum necessary sample size, the following equation was used:

$$
\begin{aligned}
\mathrm{n} & =\frac{\sigma^{2} \mathrm{Z}_{\alpha}{ }^{2}}{\mathrm{del}^{2}} \\
& =\frac{39.69 * 2.706}{25}=4.35 \approx 5 \text { subjects }
\end{aligned}
$$

$$
\begin{aligned}
& \text { Where : } \\
& \begin{array}{l}
\sigma=6.30 \mathrm{dBA} \\
\text { del }=5 \mathrm{dBA} \\
\alpha=5 \%
\end{array}
\end{aligned}
$$

\begin{tabular}{|c|c|c|}
\hline Independent Variable & Unit & Values \\
\hline Weights (Weight $\left.{ }_{\text {muff }}\right)$ & grams & $200,400,600,800,1000$ and 1200 \\
\hline Subject Face Width $\left(\mathrm{S}_{\text {width }}\right)$ & centimeters & $13.4,13.7,13.9,14.5,15.4,15.7$ \\
\hline Subject Face Height $\left(S_{\text {height }}\right)$ & centimeters & $10.9,11.6,12.3,12.6,12.8,13.2$ \\
\hline Clamping force of the 4 muffs (Force muff) & pound-force & $1.5-2.9$ \\
\hline Frequency (Freqmuffadjusted) & hertz & $\begin{array}{l}125,250,500,1000,2000,4000 \\
8000, \mathrm{dBA}\end{array}$ \\
\hline
\end{tabular}

As it happened, nine (9) subjects were recruited, but six (6) completed all testing.

Table 3: List of Independent Variables

The study investigated the influence of Total Force on the performance of earmuffs by the incremental reduction in force using weights. The independent variables involved in this study are listed in Table 3. 


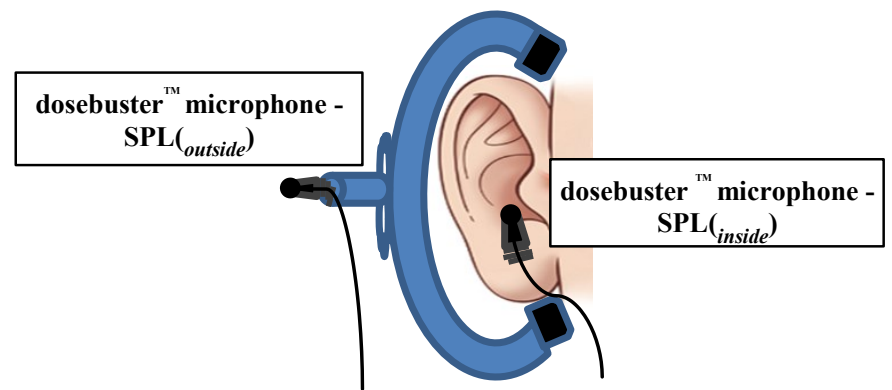

Figure 8a: dosebuster ${ }^{\mathrm{TM}}$ microphone placement

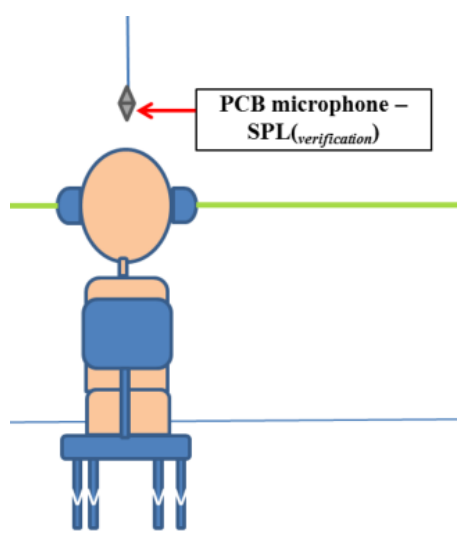

Figure 8b: PCB microphones

The dependent variable for this study was the noise reduction (NR) provided by each of 4 earmuffs worn by 6 subjects. The noise reduction values were obtained by measuring sound pressure levels (SPL) simultaneously inside (SPLinside) and outside (SPLoutside) the earmuff (see Figure 8a).

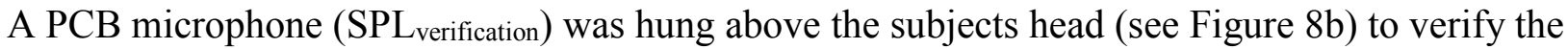
SPL being read from the microphone on the outside of the earmuff.

\section{RESULTS \& DISCUSSION}

The NR values in most cases were at least as high as the corresponding NRR value (see Figure 8).

Table 4a: Subject mean NR

\begin{tabular}{ll}
\hline Subject & Mean \\
\hline 1 & 26.98 \\
2 & 26.88 \\
3 & 26.26 \\
4 & 23.51 \\
5 & 24.37 \\
6 & 26.57 \\
\hline Total & 25.76
\end{tabular}

Table 4b: MuffID mean NR

\begin{tabular}{ll}
\hline MuffID & Mean \\
\hline 3M & 23.22 \\
Bilsom & 26.36 \\
MSA & 22.96 \\
Peltor & 29.47 \\
\hline Total & 25.50
\end{tabular}

As shown in Table 4a, Subject 1 was $0.10 \mathrm{dBA}$ higher than the next highest NR for a subject. Surprisingly, Subject 6, who is a male with the largest head in both width and height, had a lower overall mean (26.57) than Subject 1(26.98) who was a female with smaller head dimensions. 
This may be attributed to the design of the muff and its ability to accommodate a wider range of facial dimensions.

As shown in Table 4b, compared to the mean NR values for the $3 \mathrm{M}$ and MSA muffs, the Bilsom's values were over $3 \mathrm{dBA}$ higher and the Peltor was more than $6 \mathrm{dBA}$ higher. Those are substantial differences. The mean data does correspond to the muff NRR values.

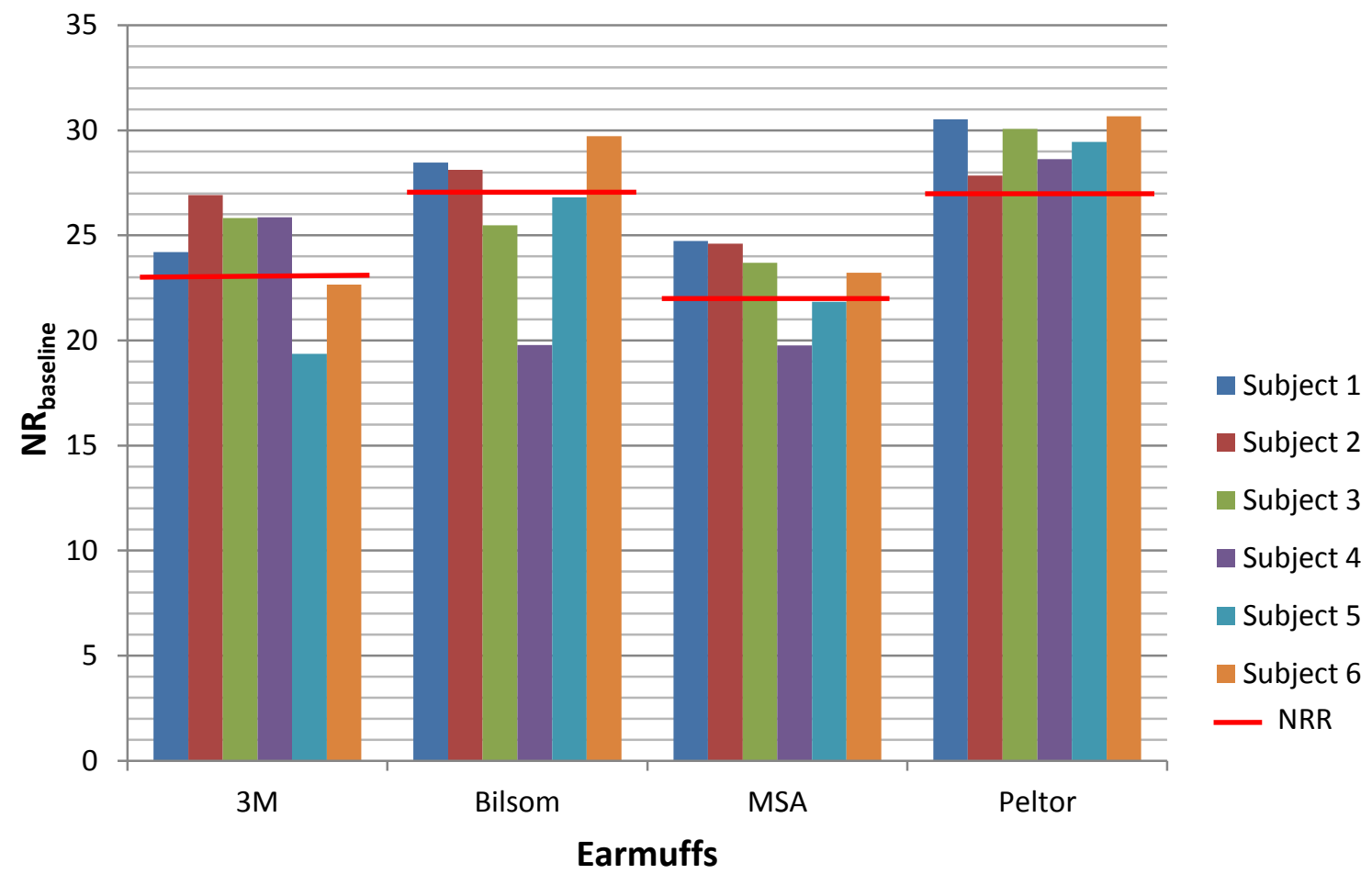

Figure 9: NR observed for each subject and each earmuff

Figure 9 shows the $\mathrm{NR}_{\text {Baseline }}$ achieved by each of the subjects for each of the muffs. $\mathrm{NR}_{\text {baseline }}$ is the measured NR values with no weights applied (muff clamp force). The vertical (red) line represents the manufacturers NRR. In most cases the subjects met or exceeded the NRR. In the case of the Peltor, all subjects exceeded the NRR value. Peltor's NR for half of the subjects reached an NR value of $30 \mathrm{dBA}$. The lowest value for the earmuffs was $19 \mathrm{dBA}$ for the $3 \mathrm{M}, 20$ dBA for the Bilsom, $20 \mathrm{dBA}$ for the MSA, and $27 \mathrm{dBA}$ for the Peltor. 


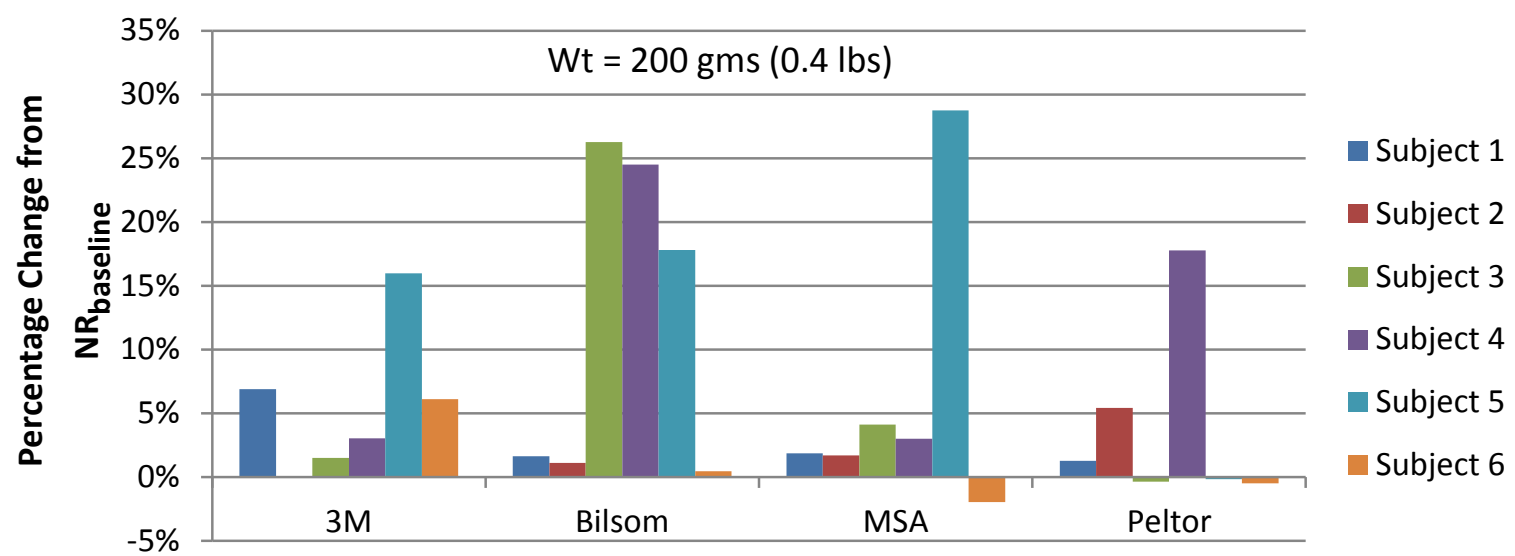

Earmuffs

Figure 10: Comparison of each subject's percentage change from $\mathrm{NR}_{\text {baseline }}$ at $200 \mathrm{gm}(0.4 \mathrm{lbs})$

Figure 10 illustrates the percentage of change in $\mathrm{NR}$ from $\mathrm{NR}_{\text {baseline }}$ to a reduction in clamp force of $200 \mathrm{gm}(0.4 \mathrm{lbs})$ for each muff-subject combination. NR values for Subject 6 , who had the largest head, appears to be mostly unaffected by the level of TotalForce. The NR for Subject 5 was greatly impacted by adding 200 gm of weight. This subject appeared to have a greater sensitivity to a minor change in force for all the muffs except the Peltor. The MSA muff seems to be the least impacted for all the Subjects except for Subject 5, whose NR was substantially changed. This was possibly due to this female subject using the regular sized helmet when the smaller cap would have provided a much better fit. It was observed for the female subjects that the regular sized cap (at the smallest adjustment) rested on the top of the Muff. This did not allow the Muff to sit correctly on the head and affected the NR. The smaller cap provided the female subjects with a better muff fit and thus better attenuation. 


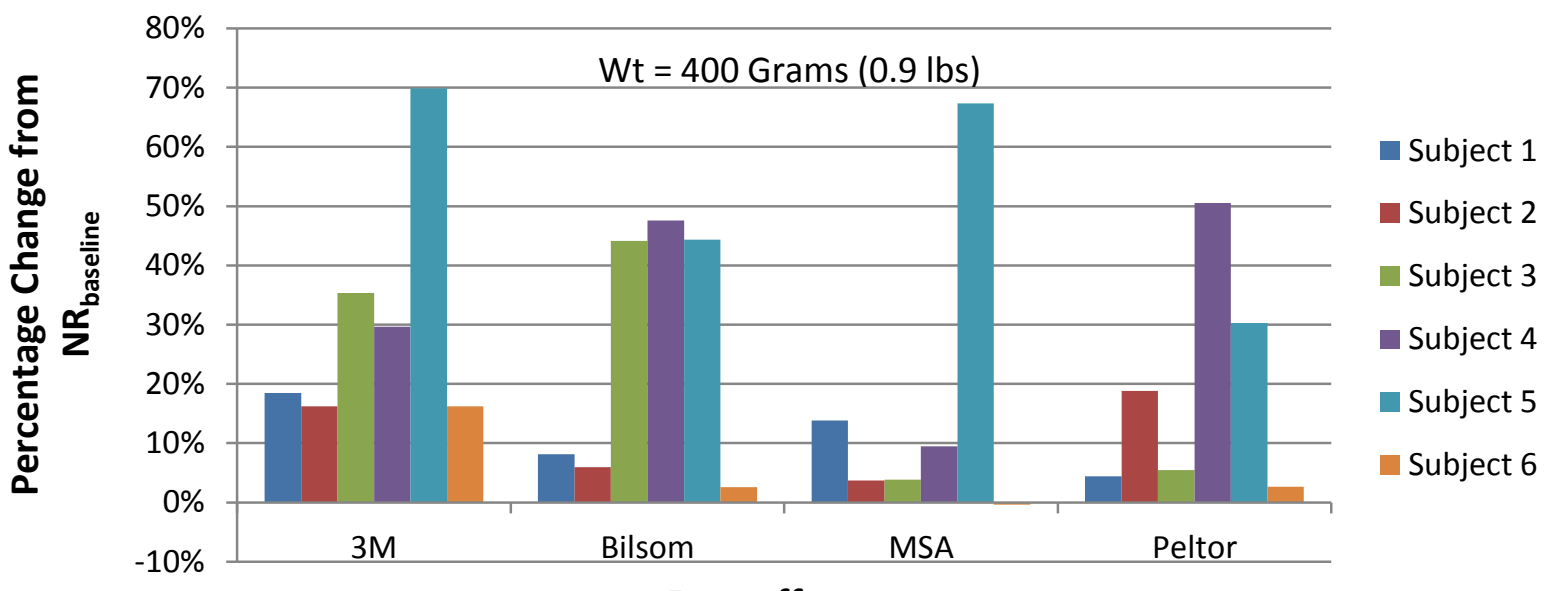

Earmuffs

Figure 11: Comparison of each subject's percentage change from $\mathrm{NR}_{\text {baseline }}$ at $400 \mathrm{gm}(0.9 \mathrm{lb})$

When examining the change from $\mathrm{NR}_{\text {baseline }}$ to a reduction in clamp force of $400 \mathrm{gm}(0.9 \mathrm{lbs})$ (see Figure 11), the attenuation of the MSA over-the head-earmuff was not greatly impacted by the change in force except for Subject 5. As stated previously, this subject was likely wearing a regular sized helmet. A change in NR occurred for all Subject 5 muffs and showed the largest loss of $70 \% \mathrm{NR}$ for the $3 \mathrm{M}$ muff. This subject appeared to be the most sensitive to a change in force across the board. Subject 6 was mostly unaffected. 


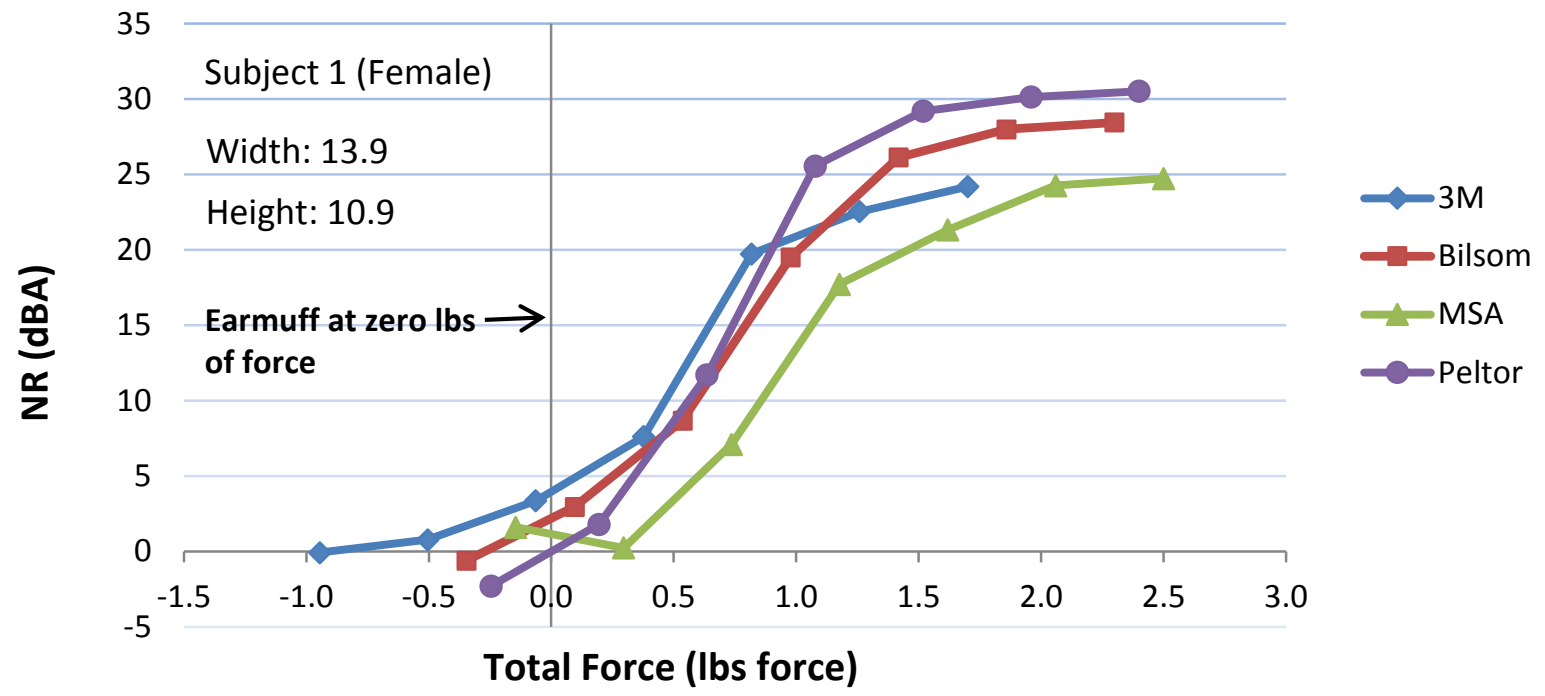

Figure 12 : NR values for Subject 1 (Female) for 4 muffs

Figure 12 illustrates the NR values achieved by Subject 2 for Total Force $($ Total Force $=$ clamp force - weight). Zero (0), indicated on the on the x-axis, represents the point at which the weights applied have equaled the clamp force of the earmuff. The negative NR values observed below the zero (0) on the y-axis represent an amplification of sound. A negative Total Force indicated in most cases that earmuff was no longer in contact with the subjects head.

NR values for Subject 2 show a classic S-curve when increasing levels of force are applied to the muffs. In this case, for three of the four muffs, the attenuation afforded to Subject 2 was not affected until the TotalForce fell to $1-1.5 \mathrm{lbs}$. This may support Warwick's idea (Warwick 2007) that the purpose of clamp force is merely to hold the muff in place. 


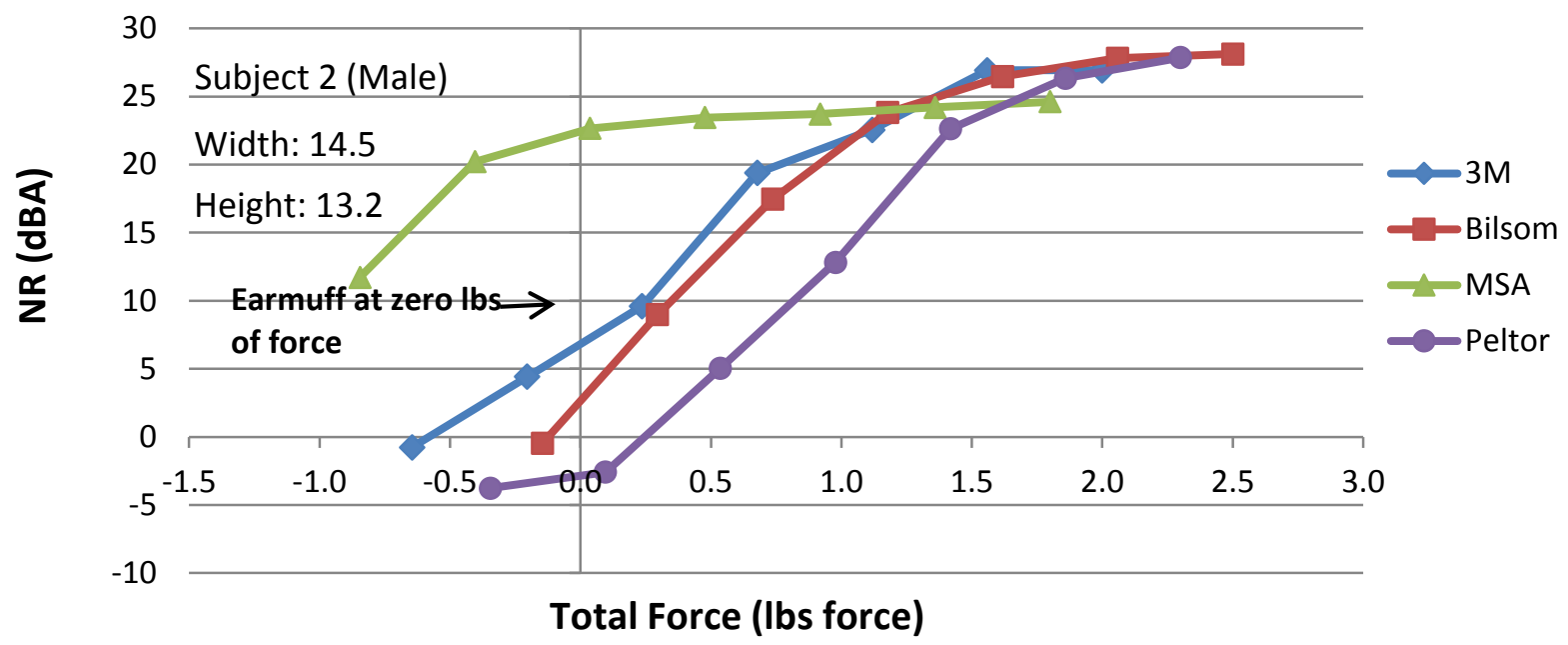

Figure 13: NR values for Subject 2 (Male) for 4 muffs

As shown in Figure 13, the results for Subject 2 show similar S-curve patterns to those found for Subject 1, with the exception of the MSA values, which show little effect from reducing the total force. Note that NR $>0$ even when Total Force $\leq 0$. However, this subject showed high attenuations for low forces with all muffs, possibly due to the high adiposity of the face allowing the cushion to still contact the face, providing a seal.

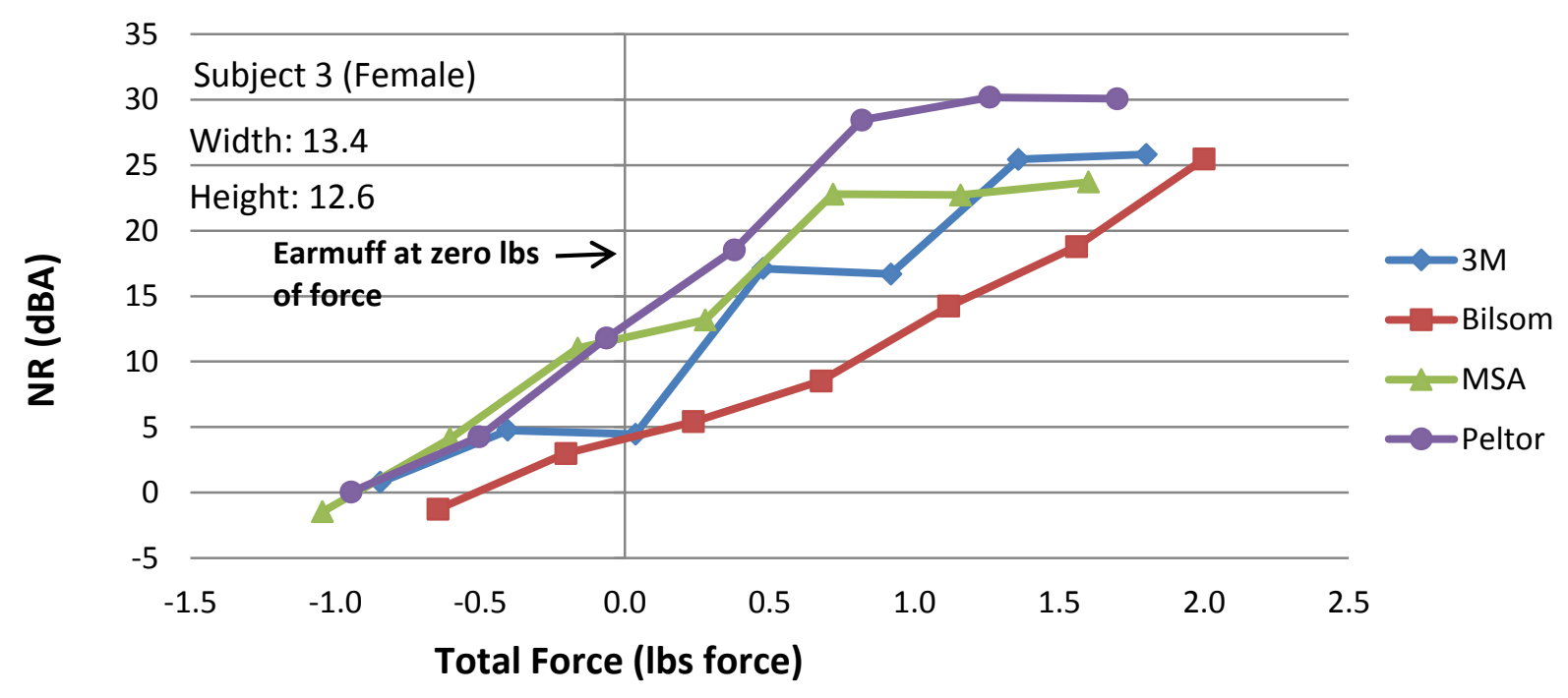

Figure 14: NR values for Subject 3 (Female) for 4 muffs 


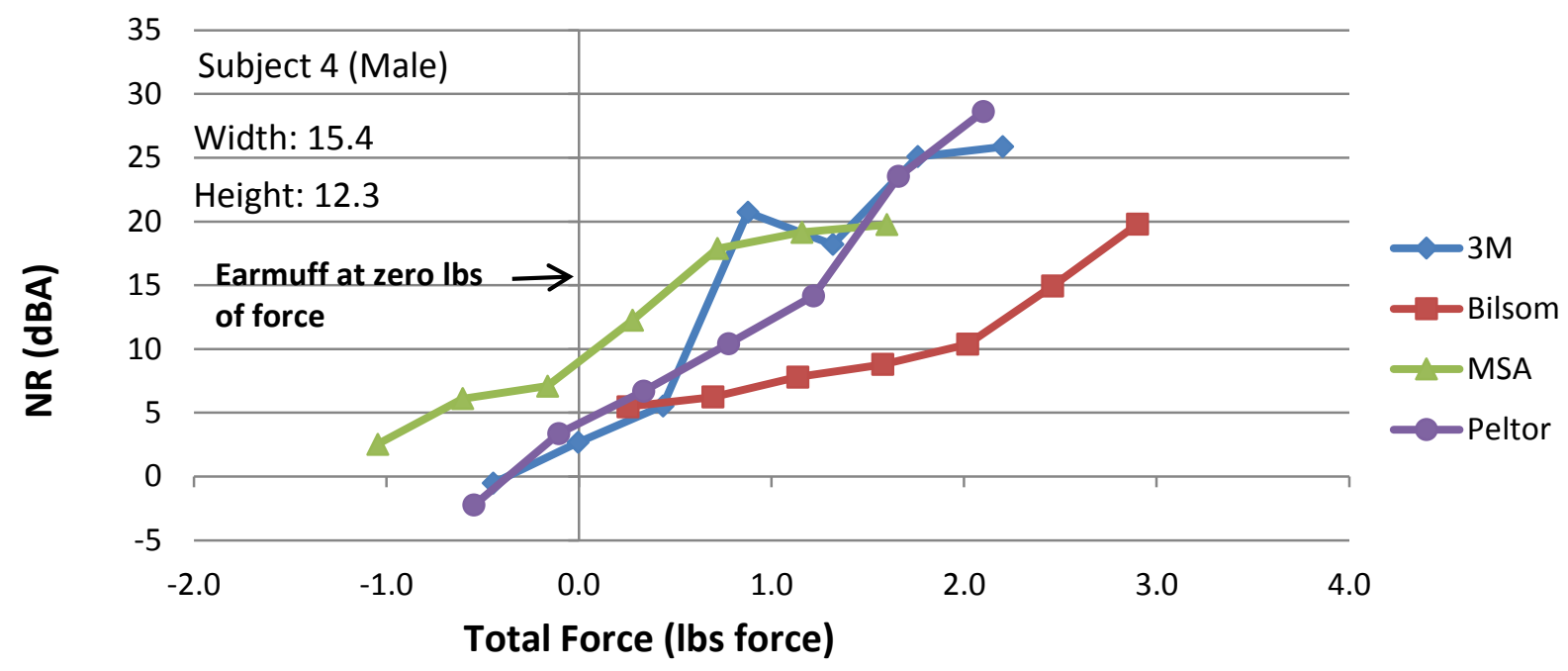

Figure 15: NR values for Subject 4 (Female) for 4 muffs

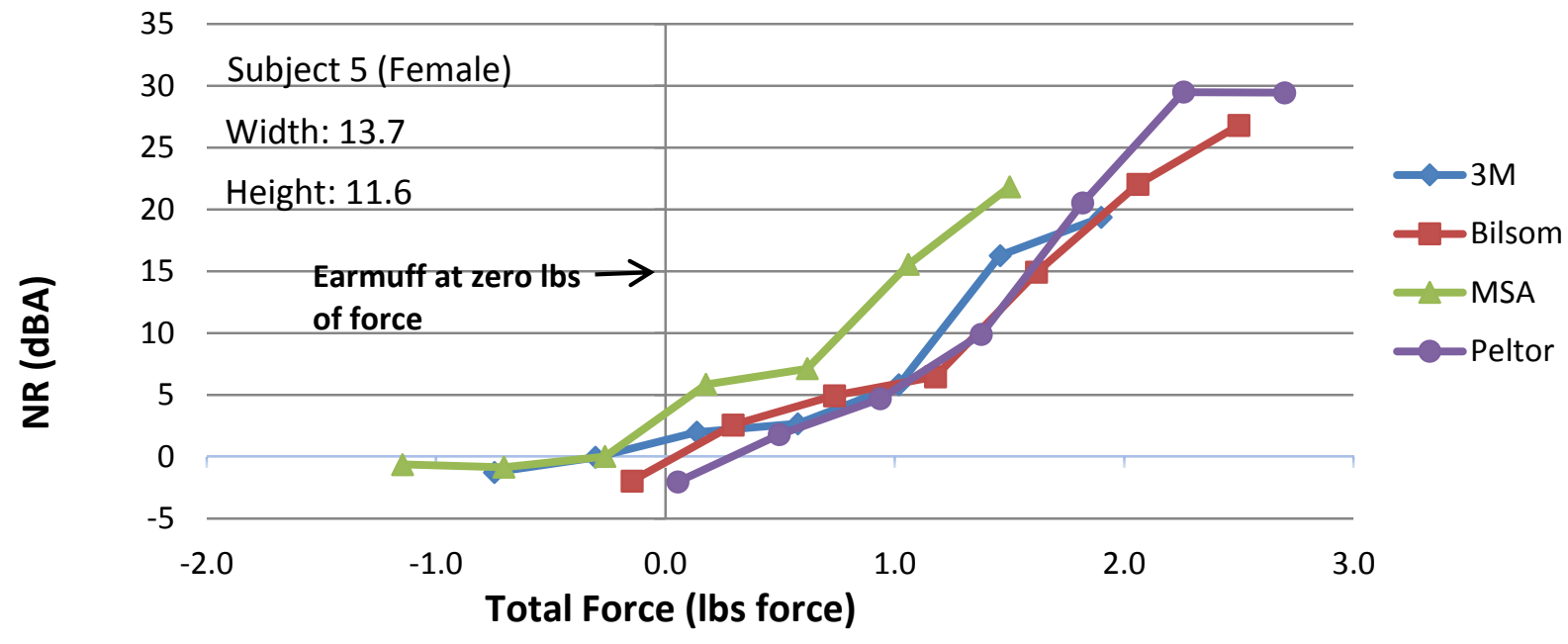

Figure 16: NR values for Subject 5 (Female) for 4 muffs 


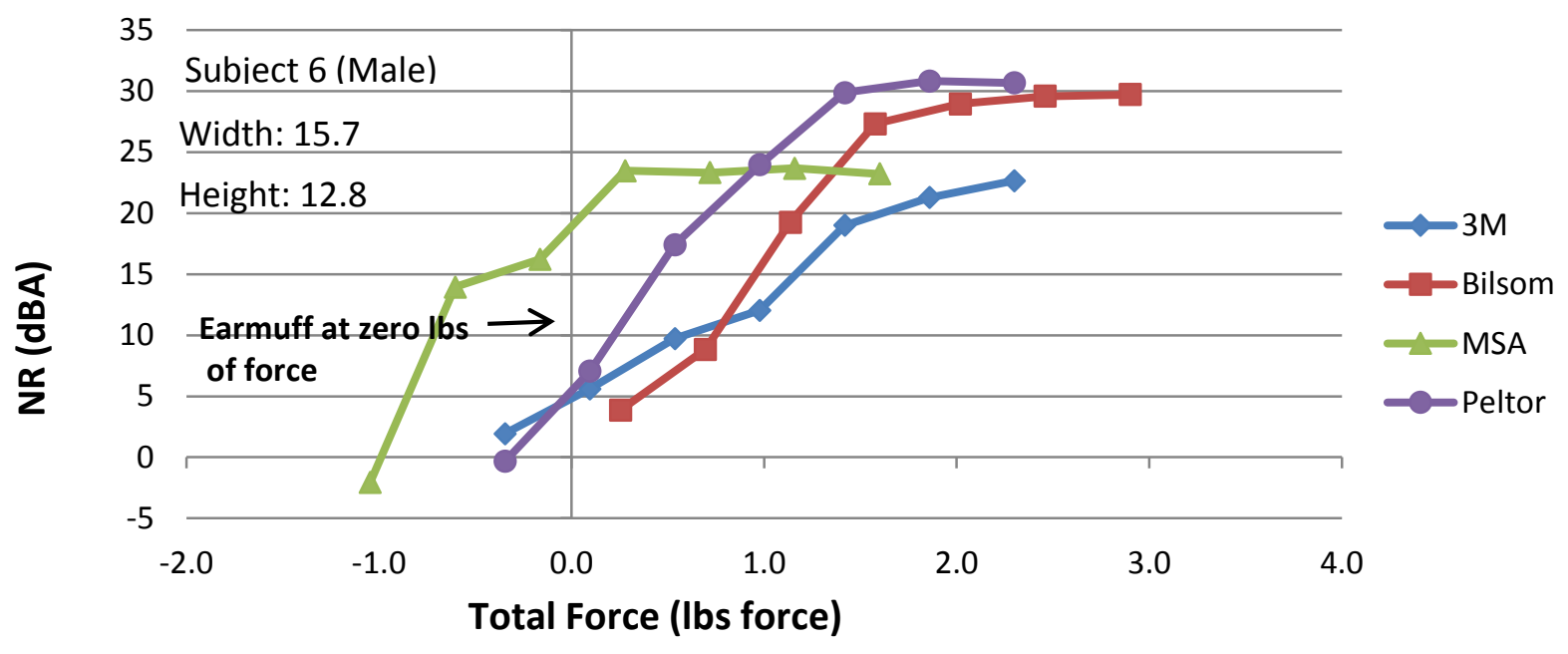

Figure 17: NR values for Subject 6 (Male) for 4 muffs

As shown in Figures 14-17, the results for the other subjects showed a similar pattern of decreasing Total Force resulting decreasing NR. Subject 6 (see Figure 16) showed high attenuation even at very low Total Force values. This subject was very tall and had a very large head, which may have improved the seal of his muffs to the face.

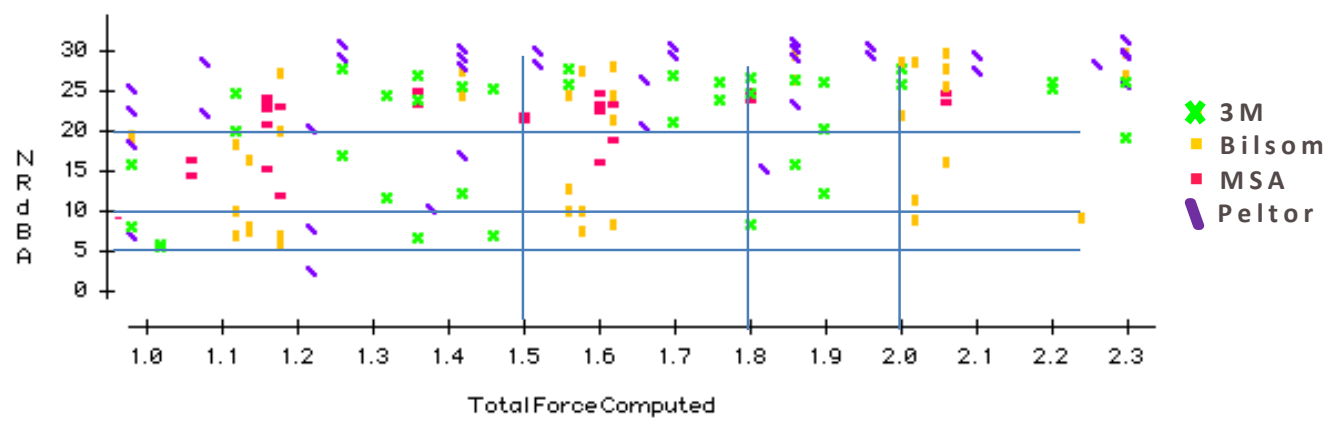

Figure 18: Data for all tests

Figure 18 shows the NR results from all combinations of muff and subject (replications averaged together). Note that the Bilsom did not always provide NR $>10$ even when TotalForce $>2 \mathrm{lbs}$. The 3M did not always provide NR $>10 \mathrm{dBA}$ even at 1.8-1.9 lbs of force. At TotalForce $>1.4$ lbs, the Peltor and MSA always provide NR values above 15. Hence, only the Peltor and MSA reliably provided a high degree of protection. It is important to note that one can expect lower performance in daily use on the job than in a laboratory setting (Durkt 1993). 
This data also suggests that the Subject or the wearer may play a large role in HPD effectiveness. In some cases an individual donning an earmuff may not achieve the expected protection, even at a de-rated value. Fit testing of a HPD is critical in verifying a wearer is actually able to achieve the expected protection. As is the case with all tight-fitting, negative-pressure respirators, fit testing must be performed to determine if a wearer can in fact achieve the minimum protection necessary.

\section{Statistical Analysis}

All statistical analysis was done using DataDesk (Odessa, NY) statistical software. Analysis of variance (ANOVA) was used to examine NR data for the subjects and muffs.

\section{Table 5: Results for factor Total Force}

\begin{tabular}{llrlrl}
\hline Source & df & $\begin{array}{l}\text { Sums of } \\
\text { Squares }\end{array}$ & $\begin{array}{l}\text { Mean } \\
\text { Square }\end{array}$ & F-ratio & Prob \\
\hline Const & 1 & 64176.8 & 64176.8 & 1190.9 & 0.0001 \\
TotalForce & 1 & 6895.78 & 6895.78 & 127.96 & 0.0001 \\
Error & 227 & 12232.7 & 53.8886 & & \\
Total & 228 & 19128.5 & & & \\
& Rsq $=$ & $56 \%$ & & &
\end{tabular}

Looking specifically at the total force of the muff as a predictor of NR (see Table 5), the low coefficient of determination (Rsq) value of 56\% suggests that variables other than total force are also important. The coefficient for the model was 8.57, the standard error was 0.67 and the t-ratio was 12.8 . 
Table 6: Results when MuffID, Total Force, Subject are added to the Model for 0 - 2.3 lbs

\begin{tabular}{lccccc}
\hline Source & df & $\begin{array}{c}\text { Sums of } \\
\text { Squares }\end{array}$ & Mean Square & F-ratio & Prob \\
\hline Const & 1 & 76399.8 & 76399.8 & 2777 & $\square 0.0001$ \\
MuffID & 3 & 1269.72 & 423.241 & 15.384 & $\square 0.0001$ \\
TotalForce & 1 & 10024.5 & 10024.5 & 364.37 & $\square 0.0001$ \\
Subject & 5 & 2579.08 & 515.815 & 18.749 & $\square 0.0001$ \\
MuffID*Subject & 15 & 2715.2 & 181.013 & 6.5794 & $\square 0.0001$ \\
Error & 224 & 6162.71 & 27.5121 & & \\
Total & 248 & 21289.9 & & & \\
& Rsq $=$ & $71 \%$ & & &
\end{tabular}

As shown in Table 6, for the entire range of force $(0-2.3 \mathrm{lbs})$ MuffId, Subject, TotalForce and the interaction of Subject and MuffId are all highly significant $(\mathrm{p}<0.1 \%)$. The Rsq for this model is $71 \%$, suggesting that other variables may explain still more of the variation in NR values.

Table 7: Results when MuffID, Total Force, Subject are added to the Model for 1.5 - 2.3 lbs

\begin{tabular}{llllll}
\hline Source & df & $\begin{array}{l}\text { Sums of } \\
\text { Squares }\end{array}$ & Mean Square & F-ratio & Prob \\
\hline Const & 1 & 51237 & 51237 & 3124 & 0.0001 \\
MuffID & 3 & 362.374 & 120.791 & 7.3649 & 0.0003 \\
TotalForce & 1 & 218.119 & 218.119 & 13.299 & 0.0005 \\
Subject & 5 & 402.441 & 80.4881 & 4.9076 & 0.0007 \\
MuffID*Subject & 15 & 974.002 & 64.9335 & 3.9592 & 0.0001 \\
Error & 65 & 1066.05 & 16.4008 & & \\
Total & 89 & 3532.62 & & & \\
& Rsq $=$ & $70 \%$ & & &
\end{tabular}

The model in Table 7 including a range of force from $1.5-2.3$ lbs shows significance $(\mathrm{p}<0.1 \%)$ for MuffID, Subject, Total Force and the interaction of Subject and MuffID. The Rsq for this model is $70 \%$, suggesting again that other variables may explain variations in NR values. Examining the ANOVA using face width and height instead of subject produced a much lower Rsq value. 
Table 8: Scheffe Post Hoc Test - Differences between MuffID

\begin{tabular}{llll}
\hline MuffID & Difference & std. err. & Prob \\
\hline Bilsom - 3M & -1.057 & 1.220 & 0.861 \\
MSA - 3M & 0.761 & 1.474 & 0.966 \\
MSA - Bilsom & 1.818 & 1.426 & 0.655 \\
Peltor - 3M & 4.303 & 1.307 & $\mathbf{0 . 0 1 8}$ \\
Peltor - Bilsom & 5.359 & 1.171 & $\mathbf{0 . 0 0 0 4}$ \\
Peltor - MSA & 3.541 & 1.499 & 0.145
\end{tabular}

Based on the results in Table 8, from the Scheffe Post Hoc Test from the model in Table 7, the Peltor appears to be statistically and significantly larger than $3 \mathrm{M}$ and Bilsom $(\mathrm{p}<0.018$ and $\mathrm{p}<$ 0.0004). The Peltor however was not significantly different from the MSA.

Table 9: Scheffe Post Hoc Test - Differences between Subjects

\begin{tabular}{clll}
\hline $\begin{array}{c}\text { Subject } \\
\text { Comparisons }\end{array}$ & Difference & std. err. & Prob \\
\hline $2-1$ & 0.184 & 1.519 & 0.999999 \\
$3-1$ & -1.650 & 1.683 & 0.964518 \\
$3-2$ & -1.833 & 1.701 & 0.947032 \\
$4-1$ & -5.422 & 1.515 & $\mathbf{0 . 0 3 5 4 5 6}$ \\
$4-2$ & -5.605 & 1.541 & $\mathbf{0 . 0 3 0 7 1 3}$ \\
$4-3$ & -3.772 & 1.678 & 0.418975 \\
$5-1$ & -4.558 & 1.574 & 0.15277 \\
$5-2$ & -4.742 & 1.601 & 0.134745 \\
$5-3$ & -2.908 & 1.751 & 0.736311 \\
$5-4$ & 0.864 & 1.595 & 0.99766 \\
$6-1$ & -0.274 & 1.574 & 0.999991 \\
$6-2$ & -0.458 & 1.601 & 0.999896 \\
$6-3$ & 1.376 & 1.756 & 0.986832 \\
$6-4$ & 5.148 & 1.597 & 0.079364 \\
$6-5$ & 4.284 & 1.653 & 0.257756
\end{tabular}

Examining the model when comparing differences between Subjects (see Table 9), only one Subject's NR was significantly smaller than two others. No other comparisons were significant. 
Table 10: Coefficients for Model for $\mathrm{NR}_{\mathrm{dBA}}$ for 0-2.3 lbs Total Force

\begin{tabular}{|c|c|c|c|c|c|}
\hline Covariate & Levels & Coefficient & std. err. & t Ratio & prob \\
\hline Total Force & Continuous & 9.702 & 0.5083 & 19.09 & 0.0001 \\
\hline \multirow[t]{4}{*}{ MuffID } & $3 \mathrm{M}$ & -1.01 & 0.5684 & -1.777 & 0.077 \\
\hline & Bilsom & -3.222 & 0.5849 & -5.508 & 0.0001 \\
\hline & MSA & 3.106 & 0.6209 & 5.003 & 0.0001 \\
\hline & Peltor & 1.125 & 0.6039 & 1.864 & 0.0637 \\
\hline \multirow[t]{6}{*}{ Subject } & 1 & 0.3376 & 0.7199 & 0.469 & 0.6395 \\
\hline & 2 & 3.565 & 0.7458 & 4.78 & 0.0001 \\
\hline & 3 & 2.58 & 0.7657 & 3.369 & 0.0009 \\
\hline & 4 & -3.437 & 0.7401 & -4.644 & 0.0001 \\
\hline & 5 & -5.563 & 0.807 & -6.893 & 0.0001 \\
\hline & 6 & 2.519 & 0.8012 & 3.144 & 0.0019 \\
\hline \multirow[t]{24}{*}{ MuffID*Subject } & $1,3 \mathrm{M}$ & 0.2234 & 2.066 & 0.1082 & 0.9142 \\
\hline & 1,Bilsom & 3.047 & 1.616 & 1.886 & 0.0638 \\
\hline & $1, \mathrm{MSA}$ & -3.434 & 1.649 & -2.082 & 0.0413 \\
\hline & 1,Peltor & 0.1631 & 1.513 & 0.1078 & 0.9145 \\
\hline & $2,3 \mathrm{M}$ & 2.272 & 1.692 & 1.343 & 0.1841 \\
\hline & 2,Bilsom & 2.234 & 1.487 & 1.502 & 0.138 \\
\hline & $2, \mathrm{MSA}$ & -0.9099 & 2.09 & -0.4354 & 0.6647 \\
\hline & 2,Peltor & -3.596 & 1.669 & -2.155 & 0.0349 \\
\hline & $3,3 \mathrm{M}$ & -2.882 & 1.885 & -1.529 & 0.1312 \\
\hline & 3,Bilsom & -1.739 & 1.632 & -1.066 & 0.2906 \\
\hline & $3, \mathrm{MSA}$ & 1.15 & 2.151 & 0.5348 & 0.5946 \\
\hline & 3,Peltor & 3.47 & 2.104 & 1.649 & 0.104 \\
\hline & $4,3 \mathrm{M}$ & 5.276 & 1.684 & 3.132 & 0.0026 \\
\hline & 4,Bilsom & -8.484 & 1.441 & -5.889 & 0.0001 \\
\hline & $4, \mathrm{MSA}$ & 1.022 & 2.087 & 0.4898 & 0.6259 \\
\hline & 4,Peltor & 2.186 & 1.67 & 1.309 & 0.1951 \\
\hline & $5,3 \mathrm{M}$ & -0.9285 & 1.84 & -0.5046 & 0.6156 \\
\hline & 5,Bilsom & 0.7923 & 1.525 & 0.5194 & 0.6052 \\
\hline & $5, \mathrm{MSA}$ & 2.847 & 2.147 & 1.326 & 0.1895 \\
\hline & 5,Peltor & -2.71 & 1.866 & -1.453 & 0.1511 \\
\hline & $6,3 \mathrm{M}$ & -3.96 & 1.729 & -2.29 & 0.0253 \\
\hline & 6,Bilsom & 4.149 & 1.8 & 2.305 & 0.0244 \\
\hline & 6,MSA & -0.6755 & 2.127 & -0.3175 & 0.7518 \\
\hline & 6,Peltor & 0.4868 & 1.702 & 0.2861 & 0.7757 \\
\hline
\end{tabular}


Table 11: Coefficients for Model for $\mathrm{NR}_{\mathrm{dBA}}$ for 1.5-2.3 lbs Total Force

\begin{tabular}{|c|c|c|c|c|c|}
\hline Covariate & Level & Coefficient & std. err. & t Ratio & prob \\
\hline Total Force & Continuous & 5.883 & 1.613 & 3.647 & 0.0005 \\
\hline \multirow[t]{4}{*}{ MuffID } & $3 \mathrm{M}$ & -1.002 & 0.8084 & -1.239 & 0.2197 \\
\hline & Bilsom & -2.059 & 0.7313 & -2.815 & 0.0065 \\
\hline & MSA & -0.2405 & 0.9614 & -0.2502 & 0.8032 \\
\hline & Peltor & 3.301 & 0.8015 & 4.118 & 0.0001 \\
\hline \multirow[t]{6}{*}{ Subject } & 1 & 1.953 & 0.9827 & 1.988 & 0.0511 \\
\hline & 2 & 2.137 & 1.009 & 2.118 & 0.038 \\
\hline & 3 & 0.3036 & 1.162 & 0.2614 & 0.7946 \\
\hline & 4 & -3.468 & 0.9988 & -3.473 & 0.0009 \\
\hline & 5 & -2.605 & 1.064 & -2.449 & 0.017 \\
\hline & 6 & 1.679 & 1.065 & 1.576 & 0.1198 \\
\hline \multirow[t]{24}{*}{ MuffID*Subject } & $1,3 \mathrm{M}$ & 0.2234 & 2.066 & 0.1082 & 0.9142 \\
\hline & 1,Bilsom & 3.047 & 1.616 & 1.886 & 0.0638 \\
\hline & 1,MSA & -3.434 & 1.649 & -2.082 & 0.0413 \\
\hline & 1,Peltor & 0.1631 & 1.513 & 0.1078 & 0.9145 \\
\hline & $2,3 \mathrm{M}$ & 2.272 & 1.692 & 1.343 & 0.1841 \\
\hline & 2,Bilsom & 2.234 & 1.487 & 1.502 & 0.138 \\
\hline & 2,MSA & -0.9099 & 2.09 & -0.4354 & 0.6647 \\
\hline & 2,Peltor & -3.596 & 1.669 & -2.155 & 0.0349 \\
\hline & $3,3 \mathrm{M}$ & -2.882 & 1.885 & -1.529 & 0.1312 \\
\hline & 3,Bilsom & -1.739 & 1.632 & -1.066 & 0.2906 \\
\hline & 3,MSA & 1.15 & 2.151 & 0.5348 & 0.5946 \\
\hline & 3,Peltor & 3.47 & 2.104 & 1.649 & 0.104 \\
\hline & $4,3 \mathrm{M}$ & 5.276 & 1.684 & 3.132 & 0.0026 \\
\hline & 4,Bilsom & -8.484 & 1.441 & -5.889 & 0.0001 \\
\hline & 4,MSA & 1.022 & 2.087 & 0.4898 & 0.6259 \\
\hline & 4,Peltor & 2.186 & 1.67 & 1.309 & 0.1951 \\
\hline & $5,3 \mathrm{M}$ & -0.9285 & 1.84 & -0.5046 & 0.6156 \\
\hline & 5,Bilsom & 0.7923 & 1.525 & 0.5194 & 0.6052 \\
\hline & 5,MSA & 2.847 & 2.147 & 1.326 & 0.1895 \\
\hline & 5,Peltor & -2.71 & 1.866 & -1.453 & 0.1511 \\
\hline & $6,3 \mathrm{M}$ & -3.96 & 1.729 & -2.29 & 0.0253 \\
\hline & 6,Bilsom & 4.149 & 1.8 & 2.305 & 0.0244 \\
\hline & $6, \mathrm{MSA}$ & -0.6755 & 2.127 & -0.3175 & 0.7518 \\
\hline & 6,Peltor & 0.4868 & 1.702 & 0.2861 & 0.7757 \\
\hline
\end{tabular}




\section{CONCLUSIONS}

1. This study provided evidence that variations in NR values will occur when the clamp force is decreased, but the degree of change is likely dependent on the muff and subject.

2. There is a great amount a variability seen between muffs and subjects. Those with the largest heads were not always afforded the greatest protection. Additionally, the earmuff with the higher clamp force did not afford the wearer the greatest protection. The results of this study showed that lower clamp forces (2-2.5 lbs.) can provide sufficient noise attenuation.

3. This study showed that clamp force alone is not a sufficient predictor for attenuation. Additionally, face width, face height and the interaction of face width and height do not sufficiently explain the variance in NR. The Total Force $(\mathrm{p}<0.0005)$, Subject $(\mathrm{p}<$ 0.0007), Muff ( $p<0.0003)$ and the interaction between Muff and Subject $(\mathrm{p}<0.0001)$ play a significant in the achieving NR values. However, the Rsq values $(\sim 70 \%)$ indicate that other variables may explain still more of the variation in NR values. The addition of adiposity could possibly improve the Rsq value.

\section{LIMITATIONS}

1. The number of subjects was not representative of the diversity of facial dimensions presented in the general population. The larger craniums of some subjects may have skewed some of the data outside of the $95^{\text {th }}$ percentile.

2. Diversity of subjects was limited. No African Americans or Hispanics participated in the study. Additionally the subjects were mostly in their mid-twenties. The age range for this study does not reflect age ranges found in the overall workforce. Older populations may have a greater tendency for increased adiposity in the face.

3. The study was performed in a controlled laboratory environment which is not reflective of real world conditions. NR measurements in a controlled setting are often greater than what is achieved in an actual work environment.

\section{RECOMMENDATIONS}

Based on the results, a practitioner should not assume that all muffs will provide adequate protection for all users. For that reason it is recommended that HPD fit tests, be used to determine a given muff provides adequate protection for a given worker. Adequacy should be based on expected exposure levels. 


\section{ACKNOWLEDGEMENTS}

I would first like thank the tireless and patient supervision and efforts of Dr. Steven Guffey through the research and seemingly endless finalization of this thesis.

I would also like to thank Dr. Ashish Nimbarte and Dr. M. Abbas Virji for their understanding, feedback and advice.

I am grateful to Ming Yu Wu for his assistance with conducting the research. I would also like to thank the subjects of the study for their time and discomfort during data collection. 


\section{REFERENCES}

ANSI, Methods for Measuring the Real-Ear Attenuation of Hearing Protectors. American National Standards Institute, S12.6-1997, New York, NY. (1997)

ANSI, Microphone-in-Real-Ear and Acoustic Test Fixture Methods for the Measurement of Insertion Loss of Circumaural Hearing Protection Devices. American National Standards Institute, S12.42-1995, New York, NY. (2004)

Berger, E.H. Hearing Protection Devices. The Noise Manual, 5th Edition, edited by E.H. Berger, L.H. Royster, J.D. Royster, D.P. Driscoll, and M. Layne. American Industrial Hygiene Association, Fairfax, VA, 379-454. (2003)

Berger E.H., Mitchell I. Measurement of the pressure exerted by earmuffs and its relationship to perceived comfort. Applied Acoustics;27:79-88 (1989)

Berger, E.H. Methods of Measuring the Attenuation of Hearing Protection Devices. The Journal of the Acoustical Society of America. Vol. 79(6) pp. 1655-87 (1986)

Casali, J.G., Grenell J.F. Noise-attenuating earmuff comfort: a brief review and investigation of band-force, cushion, and wearing-time effects. Applied Acoustics. Vol. 29(2) pp. 117-138. (1990)

Casali, J.G., Mauney, D.W., and Burks, J.A. Physical vs. Psychophysical Measurement of Hearing Protector Attenuation - a.k.a. MIRE vs. REAT. Sound and Vibration. pp. 20-27. (1995)

Durkt, G., Jr. Field Evaluation of Hearing Protection Devices at Surface Mining Environments. U.S. Department of Labor, Mine Safety and Health Administration. IR 1213, Pittsburgh, PA. (1993)

EPA. Noise Labeling Requirements for Hearing Protectors. In: Fed Regist 44(190), 40.

Washington, DC: Environmental Protection Agency. pp. 130-56, 147 (1979)

Federal Register, EPA Proposed Rule. Product Noise Labeling; Hearing Protection Devices. Vol. 74, Number 161, pp. 39149-39196. (2009)

Giardino, D.A. and Durkt, G., Jr. Evaluation of Muff-Type Hearing Protectors as Used in a Working Environment. American Industrial Hygiene Association. Vol. 57(3), pp. 264-271 (1996)

Hsu, Y., Huang C., Yo C., Chen C., Lien C. Comfort evaluation of hearing protection. International Journal of Industrial Ergonomics, 33 pp. 543-551. (2004) 
Johnson, D.J., Nixon, C.W., Skelton, M. The effect of reduced headband force on the attenuation of muff-type protectors. The Journal of the Acoustical Society of America, vol. 74, issue S1, p. S94. (1983)

Kotarbinska, E. The influence of aging on the noise attenuation of ear-muffs. Noise Health. Volume 7, Issue 26, pp. 39-45 (2005)

U.S. Department of Labor, Standards 29 CFR 1910.95 Occupational Noise Exposure. Occupational Safety and Health Standards.

Williams, W. Clamping pressure and circum-aural earmuffs. Noise Health, 9 (35), pp. 45-50. (2007)

Zannin, P. H. T., Gerges, S.N.Y., Effects of cup, cushion, headband force, and foam lining on the attenuation of an earmuff. International Journal of Industrial, Volume 36, Issue 2, pp. 165-170 (2006) 
Appendix A - Earmuff and weight Randomization Set-up

\begin{tabular}{lc}
\hline \multicolumn{2}{c}{ Earmuff } \\
\hline & \\
2 & $3 \mathrm{M}$ \\
6 & $3 \mathrm{M}$ \\
3 & Bilson \\
4 & Bilson \\
7 & MSA \\
8 & MSA \\
1 & Peltor \\
5 & Peltor \\
\hline
\end{tabular}

\begin{tabular}{ccc}
\hline \multicolumn{3}{c}{ Weight } \\
\hline Set 1 & 1 & 800 \\
& 2 & 1200 \\
& 3 & 0 \\
& 4 & 600 \\
& 5 & 400 \\
& 6 & 1000 \\
& 7 & 200 \\
Set 2 & & \\
& 1 & 400 \\
& 2 & 800 \\
& 3 & 1000 \\
& 4 & 200 \\
& 5 & 600 \\
& 6 & 0 \\
& 7 & 1200 \\
\hline
\end{tabular}

